\title{
Interaction specificity and coexpression of rice NPR1 homologs 1 and 3 (NH1 and NH3), TGA transcription factors and Negative Regulator of Resistance (NRR) proteins
}

Mawsheng Chern ${ }^{1 \dagger}$, Wei Bai ${ }^{1,2+}$, Deling Ruan ${ }^{1+}$, Taeyun Oh' ${ }^{1}$ Xuewei Chen ${ }^{1,3}$ and Pamela C Ronald ${ }^{1 *}$

\begin{abstract}
Background: The nonexpressor of pathogenesis-related genes 1, NPR1 (also known as NIM1 and SA/1), is a key regulator of SA-mediated systemic acquired resistance (SAR) in Arabidopsis. In rice, the NPR1 homolog 1 (NH1) interacts with TGA transcriptional regulators and the Negative Regulator of Resistance (NRR) protein to modulate the SAR response. Though five NPR1 homologs ( $\mathrm{NHs}$ ) have been identified in rice, only NH1 and $\mathrm{NH} 3$ enhance immunity when overexpressed. To understand why $\mathrm{NH} 1$ and $\mathrm{NH} 3$, but not $\mathrm{NH} 2$, NH4, or $\mathrm{NH} 5$, contribute to the rice immune response, we screened TGA transcription factors and NRR-like proteins for interactions specific to NH1 and NH3. We also examined their co-expression patterns using publicly available microarray data.

Results: We tested five NHs, four NRR homologs (RHs), and 13 rice TGA proteins for pair-wise protein interactions using yeast two-hybrid (Y2H) and split YFP assays. A survey of 331 inter-family interactions revealed a broad, complex protein interaction network. To investigate preferred interaction partners when all three families of proteins were present, we performed a bridged split YFP assay employing YFPN-fused TGA, YFPC-fused RH, and NH proteins without YFP fusions. We found 64 tertiary interactions mediated by NH family members among the 120 sets we examined. In the yeast two-hybrid assay, each NH protein was capable of interacting with most TGA and RH proteins. In the split YFP assay, NH1 was the most prevalent interactor of TGA and RH proteins, NH3 ranked the second, and NH4 ranked the third. Based on their interaction with TGA proteins, $\mathrm{NH}$ proteins can be divided into two subfamilies: $\mathrm{NH} 1$, $\mathrm{NH} 2$, and $\mathrm{NH} 3$ in one family and $\mathrm{NH} 4$ and $\mathrm{NH} 5$ in the other.

In addition to evidence of overlap in interaction partners, co-expression analyses of microarray data suggest a correlation between $\mathrm{NH} 1$ and $\mathrm{NH} 3$ expression patterns, supporting their common role in rice immunity. However, $\mathrm{NH} 3$ is very tightly co-expressed with $\mathrm{RH} 1$ and $\mathrm{RH} 2$, while $\mathrm{NH} 1$ is strongly, inversely co-expressed with $\mathrm{RH}$ proteins, representing a difference between $\mathrm{NH} 1$ and $\mathrm{NH} 3$ expression patterns.

(Continued on next page)
\end{abstract}

\footnotetext{
*Correspondence: pcronald@ucdavis.edu

${ }^{\dagger}$ Equal contributors

'Department of Plant Pathology and the Genome Center, University of California, Davis, CA 95616, USA

Full list of author information is available at the end of the article
} 
(Continued from previous page)

Conclusions: Our genome-wide surveys reveal that each rice NH protein can partner with many rice TGA and RH proteins and that each $\mathrm{NH}$ protein prefers specific interaction partners. $\mathrm{NH} 1$ and $\mathrm{NH} 3$ are capable of interacting strongly with most rice TGA and $\mathrm{RH}$ proteins, whereas $\mathrm{NH} 2, \mathrm{NH} 4$, and $\mathrm{NH} 5$ have weaker, limited interaction with TGA and RH proteins in rice cells. We have identified rTGA2.1, rTGA2.2, rTGA2.3, rLG2, TGAL2 and TGAL4 proteins as the preferred partners of $\mathrm{NH} 1$ and $\mathrm{NH}$ 3, but not $\mathrm{NH}$ 2, NH4, or NH5. These TGA proteins may play an important role in $\mathrm{NH} 1$ - and $\mathrm{NH3}$-mediated immune responses. In contrast, NH4 and NH5 preferentially interact with TGAL5, TGAL7, TGAL8 and TGAL9, which are predicted to be involved in plant development.

Keywords: SAR, Salicylic acid, NPR1, NH1, TGA, Protein interaction, Yeast two-hybrid, Split YFP, Co-expression, Innate immunity, Bridged split YFP, RH

\section{Background}

Plants survive pathogen attack by employing various defense strategies, including strengthening their cell walls, accumulating phytoalexins, synthesizing salicylic acid (SA), and inducing pathogenesis-related $(P R)$ gene expression. After an initial local infection, systemic acquired resistance (SAR) often occurs, which induces expression of a set of $P R$ genes, leading to a longlasting enhanced resistance against a broad spectrum of pathogens [1]. In dicots, SA and its synthetic analogs, 2,6-dichloroisonicotinic acid (INA), benzothiadiazole $(\mathrm{BTH})$, and probenazole, are potent inducers of SAR [2-4]. In monocots, SAR is induced by BTH treatment in wheat [5] and by Pseudomonas syringae in rice [6]. $\mathrm{BTH}$ also induces disease resistance in rice [7-9] and maize [10], although it is unclear if these defense responses are equivalent to SAR.

The NPR1 (nonexpressor of pathogenesis-related genes 1; also known as NIM1 and SAI1) gene is a key regulator of SA-mediated SAR in Arabidopsis [11-15]. Upon induction by SA, INA, or BTH, NPR1 expression levels increase, influencing the SAR response [16]. Arabidopsis npr1 mutants are impaired in their ability to induce $P R$ gene expression and cannot mount a SAR response even after treatment with SA or INA. NPR1 encodes a protein with a bipartite nuclear localization sequence and two proteinprotein interaction domains: an ankyrin repeat domain and a BTB/POZ domain [16]. Before activation, NPR1 forms an oligomer that is mostly excluded from the nucleus. Upon SAR induction and subsequent change to the cellular redox state, monomeric NPR1 is released and accumulates in the nucleus, activating $P R$ gene expression [17]. It has been hypothesized that NPR1 is an SA receptor that binds directly to SA, resulting in a conformational change that releases its C-terminal transcriptional activation domain and transforms the NPR1 protein into a functional transcriptional co-activator [18]. Another report suggests that NPR3 and NPR4 are the SA receptors carrying higher SA binding affinity than NPR1. In this model, NPR3 and NPR4 binding to SA triggers the Cullin 3 ubiquitin E3 ligase-mediated NPR1 degradation, which is an essential step of NPR1 function [19]. Both these models indicate that SA modulates NPR1 function.

In Arabidopsis, over-expression of NPR1 leads to enhanced disease resistance against both bacterial and oomycete pathogens [20]. In rice, over-expression of Arabidopsis NPR1 [21] or the rice ortholog NH1 [22,23] results in enhanced resistance to pathogens Xanthomonas oryzae pv. oryzae (Xoo) and Magnaporthe grisea. Introduction of an extra copy of the paralogous gene NH3 in rice also results in enhanced resistance to $\mathrm{Xoo}$, as well as hyper-responsiveness to SAR inducer treatment [24].

As previously reported, rice contains five NPR1 homologs $(\mathrm{NH})$ that can be divided into three clades: clade 1 containing $\mathrm{NH} 1$ alone, clade 2 comprised of $\mathrm{NH} 2$ and $\mathrm{NH} 3$, and clade 3 consisting of $\mathrm{NH} 4$ and $\mathrm{NH} 5$ (with NH5 duplicated in two copies present on chromosomes 11 and 12) [23,24]. Only NH1 and NH3 enhance resistance to Xoo when expressed at elevated levels [22-24]. Thus, two out of the five rice $\mathrm{NH}$ proteins are known to be involved in immunity to Xoo. NH4 and NH5 are similar to Arabidopsis BOP2 and BOP1 [24], respectively, which are mainly involved in regulating plant development [25]. No evidence suggests that NH2, $\mathrm{NH} 4$, and NH5 are involved in plant innate immunity. It is not known how $\mathrm{NH} 1$ and $\mathrm{NH} 3$ are able to confer a robust immune response while $\mathrm{NH} 2, \mathrm{NH} 4$, and $\mathrm{NH} 5$ cannot.

In search for proteins that mediate NPR1 function, several groups have identified NPR1-interaction partners. Using yeast two-hybrid assays, TGA family members of basic-region leucine zipper (bZIP) transcription factors from Arabidopsis [26,27] and rice [21] have been shown to interact with NPR1. This interaction is mediated by the ankyrin repeats of NPR1 that are necessary and sufficient for this interaction [26]. The interaction between NPR1 and TGA proteins has been demonstrated in vitro [27] and in vivo [28] to facilitate binding of the TGA proteins to the SA-responsive promoters. In vivo interaction between NPR1 and TGA2, fused to the Gal4 DNA binding domain, leads to SA-mediated 
gene activation in Arabidopsis [29]. The Arabidopsis triple knockout mutant tga2tga5tga 6 blocks SA induction of $P R$ gene expression and subsequent pathogen resistance [30]. However, TGA2, TGA5, and TGA6 function redundantly as negative regulators of $P R$ genes before induction because their triple mutant leads to higher basal levels of $P R$ gene expression [30]. NPR1 functions as a transcriptional co-activator in a TGA2-NPR1 complex after SA treatment in a transient cell assay; this function requires the $\mathrm{BTB} / \mathrm{POZ}$ domain and the oxidation of NPR1 Cys-521 and Cys-529 [31]. The $\mathrm{BTB} / \mathrm{POZ}$ domain interacts with the repression domain of TGA2 to neutralize its function [32]. The $\mathrm{BTB} / \mathrm{POZ}$ domain also serves to sequester and repress the C-terminal transactivation domain of NPR1 and SA induction releases this inhibition [18].

In Arabidopsis, three additional NIM1/NPR1 interacting proteins were identified. These proteins, named NIMIN1, NIMIN2 and NIMIN3, share very limited sequence similarity but all carry an NPR1-interaction domain [33]. Over-expression of NIMIN1 in Arabidopsis compromises SAR, while knockout and RNAsilencing of NIMIN1 results in enhanced $P R-1$ gene expression after SA treatment, indicating that NIMIN1 is a suppressor of SAR [34]. Similarly, in tobacco, overexpression of NtNIMIN2 delays PR-1 induction, while suppression of NtNIMIN2 enhances the induction of $P R-1$ [35]. In rice, we have identified an NH1 interactor: the Negative Regulator of Resistance (NRR) protein. This protein shares limited similarity with Arabidopsis NIMIN1 and NIMIN2 (approximately 20\% identity with NIMIN2 and less than $20 \%$ with NIMIN1) in the two regions required for interaction with $\mathrm{NH} 1$ and for inhibition of NH1-mediated transcriptional activation $[36,37]$. Over-expression of NRR results in hypersusceptibility to Xoo and compromises pattern recognition receptor XA21-mediated resistance to Xoo in rice [36]. Additionally, over-expression of NRR in Arabidopsis enhances susceptibility to Pseudomonas syringae DC3000 by completely blocking SAR induction [38].

To date, the TGA and NRR/NIMIN proteins are the only reported proteins that interact with Arabidopsis NPR1 and rice NH1. We have previously isolated four rice genes encoding TGA family proteins that interact with both Arabidopsis NPR1 and rice NH1 [21]. Expression of a dominant negative form of TGA2.1 in rice leads to slightly higher resistance to Xoo, indicating that rTGA2.1 alone may act as a negative regulator to basal immunity in rice [39]. The rice genome contains an additional 11 TGA-like proteins and 3 NRR homologous proteins (termed $\mathrm{RH}$ proteins). We hypothesize that these proteins differentially contribute to or regulate NH1- and NH3-mediated immunity. We set out to test this hypothesis by looking at their interaction partners.
Large-scale genome-wide protein-protein interaction surveys have previously been conducted with Arabidopsis immune regulators and microbial effectors and with rice kinases using yeast two-hybrid (Y2H) assays [40-42]. Although very useful for a global view of plant immune responses, these large-scale genome-wide surveys do not address the interaction of the TGA, $\mathrm{RH}$ and $\mathrm{NH}$ proteins. We hypothesized that a focused survey of the interaction of members of these gene families would reveal preferred partners of $\mathrm{NH} 1$ and $\mathrm{NH} 3$ and leads to insights concerning how $\mathrm{NH} 1$ and $\mathrm{NH} 3$ differ from other family members in contributing to rice immunity. We have previously reported the use of a yeast-two hybrid method and a Bimolecular Fluorescence Complementation (BiFC) assay based on split yellow fluorescence protein (YFP) $[43,44]$ to study the stress response protein interaction network consisting of 100 rice proteins [45]. BiFC has emerged as a key technique to visualize protein-protein interactions in vivo in a variety of model organisms [46]. The BiFC assay is based on reconstitution of an intact fluorescent protein when two complementary, non-fluorescent fragments of the fluorescent protein are brought together by a pair of interacting proteins. We also devised a bridged split-YFP assay to test for formation of protein complexes containing a member of each of the three families in protoplasts. Here we applied these two approaches to all members of the NH, RH, and TGA families to assess their interactions on a genome-wide scale. We found strong preferences in interaction partners for $\mathrm{NH} 1$ and $\mathrm{NH} 3$, which interact more strongly with rTGA2.1, rTGA2.2, rTGA2.3, rLG2, TGAL2 and TGAL4 and RH members than the other $\mathrm{NH}$ proteins.

\section{Results}

NH: TGA interaction profiles demonstrate selectivity in interaction partners

We previously reported the presence of five rice $\mathrm{NH}$ proteins that form three clades: $\mathrm{NH} 1$ alone in clade 1 , $\mathrm{NH} 2$ and $\mathrm{NH} 3$ in clade 2, and NH4 and NH5 in clade 3 [24]. We have also reported the isolation of four rice TGA transcription factors (rTGA2.1, rTGA2.2, rTGA2.3, and rLG2) that interact with Arabidopsis NPR1 [21] and rice $\mathrm{NH} 1$ [22] proteins. We searched available GenBank databases for other rice TGA-like (TGAL) proteins and found 11 genes encoding rice TGAL proteins (TGAL1: gi34909110; TGAL2: gi17025924; TGAL3: gi53793173; TGAL4: gi62732726; TGAL5: gi50931615; TGAL6: gi50929037; TGAL7: gi50899406; TGAL8: gi51091219; TGAL9: gi50905923; TGAL10: gi50941637; TGAL11: gi77553042). We were able to amplify full-length cDNAs for 9 of the 11 TGAL genes (TGAL1 and TGAL2 are alternative transcripts). 
To determine which TGA transcription factors are potentially involved in NH1- and NH3-triggered immunity, we investigated interactions between $\mathrm{NH}$ proteins and available TGA transcription factors using an $\mathrm{Y} 2 \mathrm{H}$ assay. We cloned each rice $\mathrm{NH}$ family member into the LexA bait vector and each TGA factor into the B42AD prey vector or vice versus and carried out $\mathrm{Y} 2 \mathrm{H}$ tests. Semiquantitative results based on the relative strength of $\beta$-galactosidase reporter activity, ranging from dark blue (marked +++ ) to white $(-)$, resulting from proteinprotein interaction are summarized in Tables 1 and 2. The original pictures of the yeast two-hybrid test results are provided in Additional file 1: Figures S1A and B. We tested 65 reciprocal combinations of $\mathrm{NH}$ and TGA proteins, yielding 62 and 48 positive interactions (blue colors). $\mathrm{NH}$ proteins interacted with all TGA proteins, with the exception of TGAL9, which interacted with only NH4 and NH5. When fused to LexA, individually, NH1, NH2, and NH3 interacted well with most TGA members except TGAL5, TGAL7, TGA8, and TGA9; the LexA-NH3 fusion also failed to interact with TGAL6. NH4 and NH5 LexA fusions interacted with most members of the TGA family, however not as strongly with rTGA2.1, rTGA2.2, and TGAL2, which showed strong interactions with NH1, $\mathrm{NH} 2$, and NH3. Notably, NH4 and NH5 both interacted well with TGAL5, TGAL7, TGAL8, and TGAL9-TGA family members that failed to interact with LexA-NH1, $\mathrm{NH} 2$, or $\mathrm{NH} 3$ fusions. Thus, interactions between $\mathrm{NH}$ and TGA family members are, in certain cases, mutually

Table 1 Summary of yeast two-hybrid results

\begin{tabular}{ccccccc}
\hline & \multicolumn{5}{c}{ B42AD fusion } \\
\cline { 2 - 6 } LexA fusion & NH1 & NH2 & NH3 & NH4 & NH5 & B42AD \\
\hline rTGA2.1 & +++ & ++ & +++ & +++ & + & - \\
rTGA2.2 & +++ & ++ & +++ & +++ & ++ & - \\
rTGA2.3 & +++ & ++ & +++ & +++ & +++ & - \\
rLG2 & +++ & ++ & +++ & +++ & +++ & - \\
TGAL1 & +++ & +++ & +++ & +++ & +++ & - \\
TGAL2 & +++ & +++ & +++ & +++ & + & - \\
TGAL4 & +++ & +++ & +++ & +++ & +++ & - \\
TGAL5 & +++ & +++ & +++ & +++ & +++ & - \\
TGAL6 & +++ & ++ & +++ & +++ & ++ & - \\
TGAL7 & ++ & +++ & +++ & +++ & +++ & + \\
TGAL8 & +++ & +++ & +++ & +++ & +++ & - \\
TGAL9 & \pm & \pm & \pm & +++ & +++ & - \\
TGAL11 & +++ & ++ & +++ & +++ & +++ & - \\
LexA & - & - & + & + & + &
\end{tabular}

Rice TGA proteins are fused to LexA and NH proteins fused to B42AD. Protein interactions between the two families were tested and semi-quantitative results recorded. At least three independent yeast colonies were included for each pair of proteins. Strong interactions as judged by dark blue colors developed from X-gal are shown as" $+++"$ and no interactions as judged by white colors indicated as "-". A subscript " + " indicates a slightly lighter blue color than a regular " + ". exclusive. Weak or negative interaction between TGA and $\mathrm{NH}$ proteins was unlikely a result of protein instability, as each NH or TGA fusion protein resulted in at least one strong interaction, indicating that all fusions are stable in yeast.

To test whether these interactions held true in planta, we carried out split YFP tests in rice protoplasts with both YFPC- and YFPN-NH and TGA fusions. Depending on which portion of YFP was fused to NH or TGA, either 49 or 31 out of 65 tests yielded positive interactions. The results are summarized in Tables 3 and 4 and the original fluorescence images provided in Additional file 2: Figures S2A and B. In fusion with either YFPC or YFPN, NH1 interacted with all TGA members, but preferred rTGA2.1, rTGA2.2, rTGA2.3, rLG2, TGAL2 and TGAL4. NH2 showed strong interactions with TGAL1, TGAL2, and TGAL11 and very weak interactions with rTGA2.2, rTGA2.3 and TGAL7, only when fused to YFPN. NH3 showed a similar TGA interaction pattern as NH1, with preferences for rTGA2.1, rTGA2.2, rTGA2.3, rLG2, TGAL2 and TGAL4. Notably, even though interactions between NH3-rTGA2.3, NH3-rLG2, NH3-TGAL2, and NH3-TGAL4 gave YFP signals of similar intensity as NH1 interactions, consistently fewer cells showed signals (see Additional file 2: Figure S2), indicating that interactions may only occur in certain cell types. NH4TGA interaction patterns were similar to $\mathrm{NH} 1$ and $\mathrm{NH} 3$, but with much weaker YFP signals and less obvious preferences for TGA partners. NH5 fused to YFPN or YFPC showed only weak interactions with some TGA members. These results suggest that protein interaction partners are more selective in the split YFP assay in rice cells than in yeast.

Because YFPC-NH2 showed no interactions with any of the TGA proteins and YFPN-NH2 showed interactions with few TGA proteins, we carried out Western blot analyses to test if the NH2 fusion proteins were unstable under these conditions. The YFPN (YN) fusion proteins were tagged with a c-Myc epitope and hence probed with an $\alpha$-c-Myc antibody; the YFPC (YC) fusion proteins were tagged with a hemaglutinin (HA) epitope and thus probed with an $\alpha-\mathrm{HA}$ antibody. The amount of protein loaded in each lane was normalized to the $\beta$ glucuronidase (GUS) activity expressed from plasmid Ubi-Gus, which was included as an internal control for protoplast transfection. Figures $1 \mathrm{~A}$ and $\mathrm{B}$ show the Western analysis results of the NH1, NH2, NH3, NH4, and NH5 fusion proteins. Each protein is marked with a white arrowhead. In Figure $1 \mathrm{~A}$, the $\mathrm{NH}$ fusion proteins were expressed alone; in Figure $1 \mathrm{~B}$, each of the $\mathrm{NH}$ fusion proteins was co-expressed with a YFPN-TGAL1 or a YFPC-TGAL1 protein. In both Figures $1 \mathrm{~A}$ and $\mathrm{B}$, the $\mathrm{NH} 1, \mathrm{NH} 4$, and NH5 proteins were stably expressed as both $\mathrm{YN}$ and $\mathrm{YC}$ fusions. The NH3 protein accumulated 
Table 2 Summary of yeast two-hybrid results

\begin{tabular}{|c|c|c|c|c|c|c|c|c|c|c|c|c|c|c|}
\hline \multirow[b]{2}{*}{ LexA fusion } & \multicolumn{14}{|c|}{ B42AD fusion } \\
\hline & B42AD & rTGA2.1 & rTGA2.2 & rTGA2.3 & rLG2 & TGAL1 & TGAL2 & TGAL4 & TGAL5 & TGAL6 & TGAL7 & TGAL8 & TGAL9 & TGAL11 \\
\hline NH1 & - & +++ & +++ & +++ & +++ & ++ & +++ & +++ & - & +++ & - & - & - & +++ \\
\hline $\mathrm{NH} 2$ & - & +++ & +++ & +++ & +++ & +++ & +++ & +++ & - & +++ & - & - & - & +++ \\
\hline NH3 & - & +++ & +++ & +++ & +++ & +++ & +++ & +++ & \pm & - & - & - & - & +++ \\
\hline $\mathrm{NH} 4$ & + & + & ++ & +++ & ++ & ++ & + & +++ & +++ & ++ & ++ & +++ & ++ & +++ \\
\hline NH5 & \pm & \pm & ++ & ++ & +++ & ++ & \pm & +++ & +++ & +++ & ++ & ++ & +++ & +++ \\
\hline LexA & - & - & - & - & - & - & - & - & \pm & - & - & - & - & - \\
\hline
\end{tabular}

Rice NH proteins are fused to LexA and TGA proteins fused to B42AD. Other criteria are as described in Table 1.

to a lesser extent, but was readily detectable under most tested conditions. The $\mathrm{NH} 2$ fusion proteins were barely detectable under all conditions. The anti-HA antibody in general gave stronger signals than the anti-Myc antibody, most likely due to the differences between these two antibodies. The anti-Myc antibody also detected non-specific bands (marked by a black * sign). These results demonstrate that the NH1, NH3, NH4, and NH5 fusion proteins are stable in vivo under the tested conditions. While the NH2 fusion proteins were less stable, the YN: $\mathrm{NH} 2$ protein was stable enough to interact with TGAL1, TGAL2, and TGAL11, leading to strong YFP signals. Therefore, even though the low $\mathrm{NH} 2$ protein levels may reduce YFP signals, the results of weak or absent signals from interactions between other TGA and NH2 fusion proteins are unlikely solely due to the absence of the $\mathrm{NH} 2$ fusion proteins.

The expression levels of YFPC fused TGA proteins alone or together with YFPN-NH1, $-\mathrm{NH} 2$, or -NH4, were examined by Western analyses and are shown in Figures $1 \mathrm{C}, \mathrm{D}, \mathrm{E}$, and F. Each protein is marked with a white arrowhead. The results suggest that the TGA proteins are all relatively stably expressed, despite variations among different TGAs. The YFP signal strengths resulted from interactions with TGA proteins are not correlated with the TGA protein levels, indicating that the expression level of a TGA protein is not the major factor determining the YFP signal strength. Notably,
TGA2.1, TGA2.2, TGA2.3, and TGAL2 showed double bands near the locations of the expected molecular weights, suggesting protein modifications. However, it remains unclear as to what modifications may have caused the generation of the multiple forms. In addition, most of the TGA proteins showed additional bands at locations of much higher molecular weights; these bands likely represent dimers of each protein even though each protein was subject to standard procedures of denaturation using SDS and reducing agent before running SDS gels. The expression levels of YFPN-NH1, $-\mathrm{NH} 2$, and - $\mathrm{NH} 4$ are consistent with previous observations: $\mathrm{NH} 1$ and $\mathrm{NH} 4$ fusion proteins are stable while $\mathrm{NH} 2$ fusion protein is unstable and appears at a very low level.

Figure 2 presents an interaction network of rice $\mathrm{NH}$ and TGA proteins, based primarily on the split YFP results, but with yeast two-hybrid results taken into consideration. Members of the TGA and NH protein families demonstrated preferences in interaction partners, prompting the classification of $\mathrm{NH}$ proteins into two main subfamilies. Figure $2 \mathrm{~A}$ focuses on major TGA interactors of $\mathrm{NH} 1, \mathrm{NH} 2$, and $\mathrm{NH} 3$ (depicted by black arrows). These TGA proteins showed lower preferences for $\mathrm{NH} 4$ and even lower preferences for NH5 (grey arrows). NH2 showed similar interaction preferences as $\mathrm{NH} 1$ in yeast two-hybrid, but failed to show strong interactions in split YFP for most TGA proteins,

Table 3 Summary of split YFP results

\begin{tabular}{|c|c|c|c|c|c|c|c|c|c|c|c|c|c|c|}
\hline \multirow{2}{*}{$\begin{array}{l}\text { YFPC } \\
\text { fusion }\end{array}$} & \multicolumn{14}{|c|}{ YFPN fusion } \\
\hline & YFPN & rTGA2.1 & rTGA2.2 & rTGA2.3 & rLG2 & TGAL1 & TGAL2 & TGAL4 & TGAL5 & TGAL6 & TGAL7 & TGAL8 & TGAL9 & TGAL11 \\
\hline NH1 & \pm & +++ & +++ & +++ & +++ & $++_{+}$ & +++ & +++ & ++ & ++ & $+_{+}$ & $+_{+}$ & $+_{+}$ & ++ \\
\hline $\mathrm{NH} 2$ & - & - & \pm & - & - & - & - & - & - & - & - & - & - & - \\
\hline NH3 & - & +++ & $++_{+}$ & $+++^{a}$ & $+++^{a}$ & ++ & $+++^{\mathrm{a}}$ & $+++^{\mathrm{a}}$ & ++ & ++ & + & + & \pm & ++ \\
\hline NH4 & - & ++ & ++ & ++ & ++ & ++ & ++ & ++ & ++ & ++ & $+_{+}$ & $t_{+}$ & $+_{+}$ & ++ \\
\hline NH5 & - & $+_{+}$ & $t_{+}$ & $+_{+}$ & ++ & + & $+_{+}$ & $+_{+}$ & $+_{+}$ & + & + & \pm & + & - \\
\hline YFPC & & + & + & + & + & \pm & - & \pm & - & \pm & - & - & - & - \\
\hline
\end{tabular}

Rice TGA proteins are fused to YFPN and NH proteins fused to YFPC. Interactions between the two families were tested and semi-quantitative results recorded. Strong interactions as judged by bright YFP fluorescence are shown as" +++" and no interactions as judged by lack of YFP fluorescence indicated as "-". "aa" indicates that signals showed in fewer cells compared to other combinations. A subscript " + " indicates a slightly weaker YFP signal than a regular " + ". 
Table 4 Summary of split YFP results

\begin{tabular}{|c|c|c|c|c|c|c|c|c|c|c|c|c|c|c|}
\hline \multirow{2}{*}{$\begin{array}{l}\text { YFPN } \\
\text { fusion }\end{array}$} & \multicolumn{14}{|c|}{ YFPC fusion } \\
\hline & YFPC & rTGA2.1 & rTGA2.2 & rTGA2.3 & rLG2 & TGAL1 & TGAL2 & TGAL4 & TGAL5 & TGAL6 & TGAL7 & TGAL8 & TGAL9 & TGAL11 \\
\hline $\mathrm{NH} 1$ & - & +++ & +++ & +++ & ++ & + & +++ & +++ & \pm & - & - & - & - & + \\
\hline $\mathrm{NH} 2$ & - & - & + & + & - & $++_{+}$ & +++ & - & - & - & + & \pm & - & +++ \\
\hline $\mathrm{NH} 3$ & - & ++ & ++ & ++ & + & + & +++ & +++ & + & - & - & - & - & - \\
\hline $\mathrm{NH} 4$ & - & + & + & + & - & \pm & ++ & ++ & + & - & - & - & + & - \\
\hline NH5 & - & + & + & - & - & - & - & - & - & - & - & - & - & - \\
\hline YFPN & - & - & - & - & - & - & - & - & - & - & - & - & - & - \\
\hline
\end{tabular}

Rice NH proteins are fused to YFPN and TGA proteins fused to YFPC. Interactions between the two families were tested. Other criteria are as described in Table 3.

except for TGAL1, TGAL2, and TGAL11 when fused to YFPN (depicted as single direction arrows). Figure 2B shows the TGA proteins that preferred $\mathrm{NH} 4$ and $\mathrm{NH} 5$, instead of $\mathrm{NH} 1, \mathrm{NH} 2$, or $\mathrm{NH}$. Thus the $\mathrm{NH}$ proteins can be roughly divided into two subfamilies based on their interaction patterns with TGA proteins: NH1, $\mathrm{NH} 2$, and $\mathrm{NH} 3$ in one family and $\mathrm{NH} 4$ and $\mathrm{NH} 5$ in the other. In summary, the split YFP and $\mathrm{Y} 2 \mathrm{H}$ results indicate that $\mathrm{NH} 1$ and $\mathrm{NH} 3$ are the major interaction partners of rice TGA proteins (depicted as solid dark lines). Interaction profiles also show that $\mathrm{NH} 1$ and $\mathrm{NH} 3$ prefer rice TGA2.1, TGA2.2, TGA2.3, LG2, TGAL2, and TGAL4 as partners and that NH2 prefers TGAL1, TGAL2, and TGAL11, while NH4 and NH5 have weak or limited interactions (shown as grey lines) with these TGA proteins. NH4 and NH5 may prefer TGAL5, TGAL7, TGAL8, and TGAL9 instead.

\section{$\mathrm{NH} 1$ and $\mathrm{NH} 3$ are the preferred interacting partners of $\mathrm{RH}$ proteins}

Four members of the NRR family in rice have been reported: NRR, RH1, RH2, and RH3 [36]. Because RH proteins potentially play a role in modulating defense, we tested interactions between $\mathrm{NH}$ proteins and $\mathrm{RH}$ proteins in $\mathrm{Y} 2 \mathrm{H}$ and split YFP. Tables 5 and 6 summarize the yeast two-hybrid results and the original pictures are provided in Additional file 3: Figures S3A and B. The $\mathrm{Y} 2 \mathrm{H}$ assay on $\mathrm{NH}-\mathrm{RH}$ interactions yielded either 16 or 18 positives out of 20 combinations, depending on which vector was used. When fused to LexA, NH1, $\mathrm{NH} 2$, and NH3 interacted strongly with NRR, RH1, and RH3, but only weakly with RH2. When fused to B42AD, $\mathrm{NH} 1, \mathrm{NH} 2$, and $\mathrm{NH} 3$ interacted with all NRR members, albeit less strongly with $\mathrm{RH} 2$. NH4 and NH5 in fusion with LexA showed only weak interactions with NRR and $\mathrm{RH} 3$, whereas in B42AD fusion, NH4 and NH5 showed interactions with RH1, RH2, and RH3, but not with NRR. These results show that NRR, RH1, and RH3 are the preferred partners of NH1, NH2 and NH3.

Tables 7 and 8 summarize the semi-quantitative spilt YFP results of interactions between $\mathrm{NH}$ and $\mathrm{RH}$ proteins. The original YFP fluorescence images are provided in Additional file 4: Figures S4A and B. Depending on which portion of YFP was fused to NH or RH family members, either 16 or 14 out of 20 combinations yielded positive interactions above control backgrounds (Table 7 and 8). Whether fused to YFPN or YFPC, NH1 and NH3 behaved similarly, interacting well with NRR, RH1, and RH3, and to a lesser extent with RH2. NH2 interacted weakly with NRR and RH2 when fused to YFPN. Significant background YFP fluorescence signals were observed when NRR and RH1 were fused to YFPN. NH4 and NH5 showed very weak or absent interactions with $\mathrm{RH}$ proteins, indicating that $\mathrm{NH} 4$ and $\mathrm{NH} 5$ may not be the preferred partners of the $\mathrm{RH}$ proteins.

We conducted Western blot analyses on $\mathrm{NH}$ proteins fused either to YFPN (YN) or YFPC (YC) in the presence of a $\mathrm{RH}$ protein and on $\mathrm{RH}$ proteins fused to the other half of the YFP protein. The results are shown in Figures 3A and $\mathrm{B}$, where each protein is marked with an arrowhead. Overall the results are similar to those presented in Figure 1. NH1, NH4 and NH5 were highly expressed; YN-NH3 was easily detectable, but at lower levels; while YN-NH2 was expressed at the lowest level and was barely detectable in many cases. In general, NRR, RH1, RH2, and RH3 were all stably expressed. Protein loadings were equalized to the GUS activity, expressed from a Ubi-Gus plasmid included as an internal control during protoplast transfection. Notably, YN-NH1, $-\mathrm{NH} 2$, and $-\mathrm{NH} 3$ fusion proteins (but not $\mathrm{YN}-\mathrm{NH} 4$ or $\mathrm{YN}-\mathrm{NH} 5$ ) were cleaved and appeared mainly at lower molecular weights (marked with a white star in Figure 3A) in the presence of YC-NRR; the reason of this cleavage is unknown.

Figure 4 presents an interaction network of the $\mathrm{NH}$ and $\mathrm{RH}$ proteins, mainly based on split YFP results. NH1 and $\mathrm{NH} 3$ are the major partners of all $\mathrm{RH}$ proteins and interact strongly (depicted as solid dark lines) with all RH proteins, except RH2 (grey lines). NH2, NH4, and NH5 only have minor interactions (grey lines) with select $\mathrm{RH}$ proteins.

A bridged split YFP assay confirms that $\mathrm{NH} 1, \mathrm{NH} 2$, and $\mathrm{NH} 3$ form complexes containing specific $\mathrm{RH}$ and TGA proteins The experiments described above suggest a broad and general capacity for interaction between members of the 


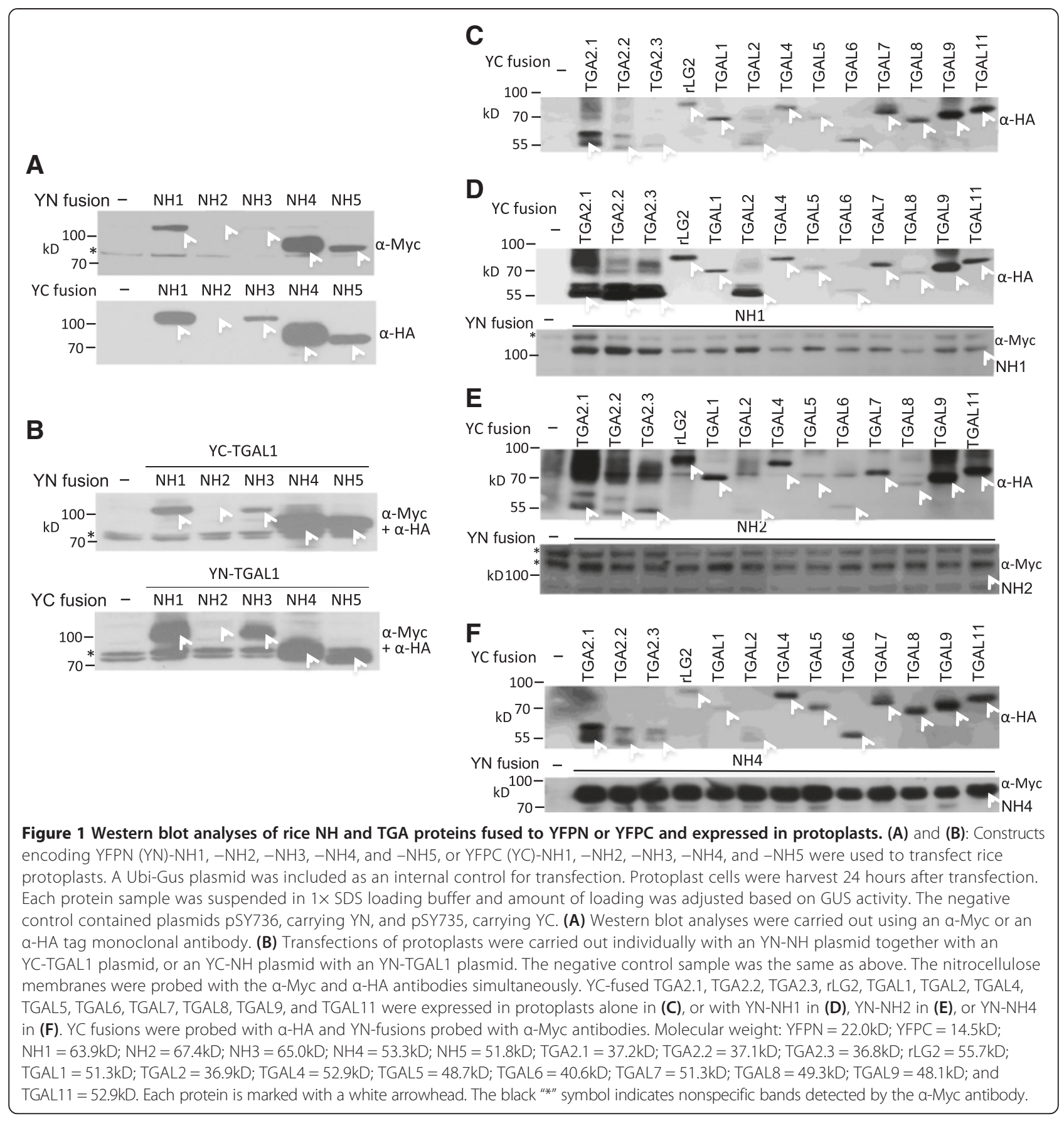

three families of proteins that are key regulators of the rice immune response. They also indicate that particular family members preferentially interact with particular subclasses of proteins. These experiments yield valuable information concerning interactions when proteins from two families are present. In order to further investigate the preferred interaction partners when all three families of proteins are present, we devised a bridged split YFP assay. No available evidence suggests that TGA and RH (or NIMIN) proteins directly interact with each other, while both interact with
$\mathrm{NH}$ proteins, as shown above. Using YFPC-fused RH proteins and YFPN fusions of the TGA proteins determined to be the major interaction partners of $\mathrm{NH}$ proteins from the split YFP assay (rTGA2.1, rTGA2.2, rTGA2.3, rLG2, TGAL2, and TGAL4), we tested whether the introduction of various $\mathrm{NH}$ proteins (non-YFP fusions) was able to facilitate interaction between YFPN and YFPC fusions, yielding a fluorescence signal.

Table 9 summarizes the semi-quantitative results of the bridged split YFP assay. The original fluorescence 
A

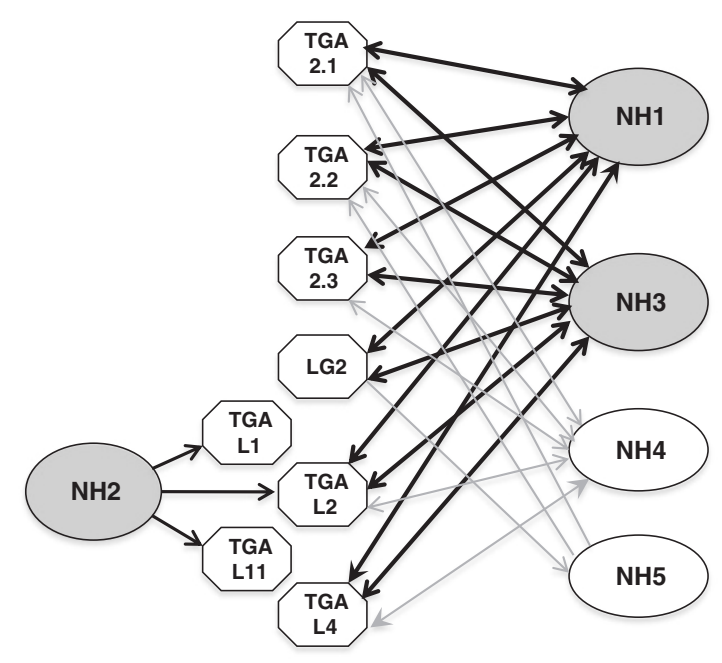

B

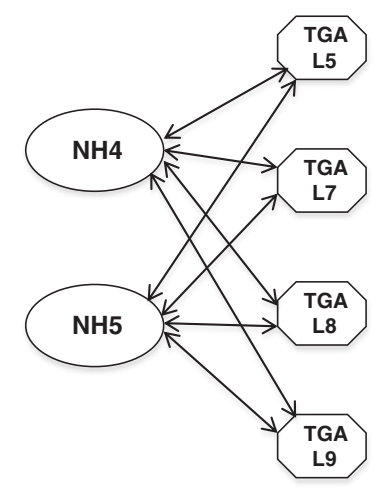

Figure 2 Interaction network between the rice NH family members and select TGA proteins. The summary is based primarily on split YFP results with $\mathrm{Y} 2 \mathrm{H}$ results taken into consideration. (A) Among the five rice $\mathrm{NH}$ proteins, $\mathrm{NH} 1$ and $\mathrm{NH} 3$ are the major interactors of the TGA proteins represented here. Strong interactions are shown as solid dark lines and weak interactions are shown as grey lines. Bidirectional arrows indicate that both YFPN and YFPC fusions interact well, while single-direction arrows indicate that only one of the fusions shows interaction in split YFP. (B) TGA interactors unique to $\mathrm{NH} 4$ and $\mathrm{NH} 5$. Presented are four TGA proteins that interact strongly with $\mathrm{NH} 4$ and NH5 in both LexA and B42AD fusions. When fused to B42AD, these TGA proteins fail to interact strongly with $\mathrm{NH1}, \mathrm{NH} 2$, and $\mathrm{NH} 3$. TGAL9 also fails to interacts with $\mathrm{NH} 1, \mathrm{NH} 2$, or $\mathrm{NH} 3$ in the LexA fusion.

images are provided in Additional file 5: Figure S5. When YFPC control and YFPN-fused TGA proteins were expressed together with $\mathrm{NH} 1, \mathrm{NH} 2, \mathrm{NH} 3, \mathrm{NH} 4$, or NH5 (expressed from the maize $U b i-1$ promoter and labeled NH1ox, NH2ox, NH3ox, NH4ox, and NH5ox), no YFP fluorescence signal was detected. Similarly, when YFPN control and YFPC-fused NRR, RH1, RH2, or RH3 were expressed with ectopic NH1, NH2, NH3, NH4, or NH5 in protoplasts, little to no YFP signal was detected. When YFPC-fused NRR was co-expressed with $\mathrm{NH}$ family members and the YFPN-fused TGA members, 15 positive interactions (only signal strengths marked " + " or higher are counted) were detected among 36 pairs of tests. Without the ectopic expression of $\mathrm{NH}$ members, only TGAL4 yielded a weak signal, indicating that TGAL4 may be a prevalent indirect partner of NRR. The weak signal probably represents the low levels of endogenous $\mathrm{NH}$ members that associate with these two proteins. When $\mathrm{NH} 1$ was ectopically introduced, strong YFP signals appeared for all YFPN-fused TGA members investigated. These results indicate that $\mathrm{NH} 1$ can form a complex with NRR and any of these TGA proteins. Introduction of NH3 into the NRR-TGA split YFP system yielded results similar to NH1, despite somewhat weaker YFP signals. These results indicate that, like NH1, NH3 can form a complex consisting of NRR and any of the TGA proteins. The slightly lower
YFP signal strengths of NH3 than NH1 were possibly due to the lower protein levels of NH3 than NH1, as detected consistently as YFP fusion proteins in Western analysis shown above. However, we cannot rule out the possibility that NH3 may actually have a lower affinity than NH1 for these TGA and NRR proteins. Consistently, much fewer cells displayed YFP signals when $\mathrm{NH} 3$ was introduced compared to NH1 (see Additional file 5: Figure S5A), further suggesting that $\mathrm{NH} 3$ may be stable only in certain, but not all, cell types. When NH2 was introduced in place of NH1 into the NRR-TGA split YFP system, no obvious effects were observed, but a weak signal increase from rTGA2.3. Introduction of NH4 or NH5 had little effect on the NRR-TGA system, indicating that $\mathrm{NH} 4$ and $\mathrm{NH} 5$ probably do not form complexes containing NRR and one of these TGA proteins.

When YFPC-fused RH1 and select YFPN-fused TGA proteins were co-introduced with $\mathrm{NH}$ family members into rice protoplasts, 19 positives were detected out of 36 tests. In the absence of NH proteins, modest YFP signals were observed for YFPN-TGAL4 while no significant signals were detected for other TGA proteins, indicating that TGAL4 is also a prevalent indirect partner for RH1. When NH1 was ectopically introduced, strong YFP signals were detected with all TGA members, indicating that $\mathrm{NH} 1$ can facilitate complex formation with $\mathrm{RH} 1$ and any of these TGA proteins. Introduction of 
Table 5 Summary of yeast two-hybrid results

\begin{tabular}{cccccc}
\hline & \multicolumn{5}{c}{ YFPC fusion } \\
\cline { 2 - 6 } LexA fusion & B42AD & NRR & RH1 & RH2 & RH3 \\
\hline NH1 & - & +++ & +++ & \pm & +++ \\
NH2 & - & +++ & +++ & + & +++ \\
NH3 & \pm & +++ & +++ & + & +++ \\
NH4 & + & ++ & + & ++ & ++ \\
NH5 & \pm & ++ & \pm & \pm & ++ \\
LexA & - & \pm & - & - & - \\
\hline
\end{tabular}

Rice $\mathrm{NH}$ proteins are fused to LexA and RH proteins fused to B42AD. Other criteria are as described in Table 1.

$\mathrm{NH} 3$ had an effect similar to the addition of NH1, suggesting that $\mathrm{NH} 3$ can also form a complex consisting of $\mathrm{RH} 1$ and any one of the six TGA proteins. Introduction of NH2, NH4, or NH5 had little to no effect on the RH1-TGA split YFP system, suggesting that these proteins do not significantly mediate the formation of complexes containing RH1 and one of the TGA proteins.

When the YFPC-RH2 fusion and select YFPN-fused TGA proteins were co-introduced with $\mathrm{NH}$ family members into rice protoplasts, 23 positive signals were detected out of 36 tests. Without ectopic NH proteins, modest signals were observed for rTGA2.1, rTGA2.3, rLG2, TGAL2, and TGAL4, indicating that RH2 can form a complex containing each of these TGA proteins. Introduction of $\mathrm{NH} 1$ strengthened the YFP signal associated with TGAL2, and to a lesser extent, the signals for rTGA2.3 and TGAL4 as well, indicating that NH1 is able to mediate complex formation with $\mathrm{RH} 2$ and TGAL2, and possibly between RH2 and rTGA2.3 or TGAL4 in protoplasts. Introduction of $\mathrm{NH} 2$ yielded strong signals for all rTGA proteins, especially for rTGA2.2, rTGA2.3, and TGAL2, indicating that NH2 is capable of forming a complex containing $\mathrm{RH} 2$ and any one of these TGA proteins. When NH3 was introduced, strong signals were observed for rTGA2.1, rTGA2.3, rLG2, TGAL2 and TGAL4, and lower signals for rTGA2.2, suggesting that NH3 can also form a complex containing $\mathrm{RH} 2$ and any of these TGA proteins. Introduction of $\mathrm{NH} 4$ and NH5 did not increase the YFP signal for any of the TGA family members tested.

Table 6 Summary of yeast two-hybrid results

\begin{tabular}{ccccccc}
\hline & \multicolumn{7}{c}{ B42AD fusion } \\
\cline { 2 - 7 } LexA fusion & $\mathrm{NH} 1$ & $\mathrm{NH2}$ & $\mathrm{NH3}$ & $\mathrm{NH} 4$ & $\mathrm{NH} 5$ & B42AD \\
\hline NRR & +++ & +++ & +++ & - & - & - \\
$\mathrm{RH} 1$ & +++ & +++ & +++ & +++ & +++ & - \\
$\mathrm{RH} 2$ & ++ & ++ & ++ & +++ & ++ & - \\
$\mathrm{RH} 3$ & +++ & +++ & +++ & ++ & ++ & - \\
\hline
\end{tabular}

Rice $\mathrm{RH}$ proteins are fused to LexA and $\mathrm{NH}$ proteins fused to B42AD. Other criteria are as described in Table 1.
Table 7 Summary of split YFP results

\begin{tabular}{cccccc}
\hline & \multicolumn{5}{c}{ YFPC fusion } \\
\cline { 2 - 6 } YFPN fusion & YFPC & NRR & RH1 & RH2 & RH3 \\
\hline NH1 & + & +++ & +++ & ++ & +++ \\
NH2 & - & ++ & - & ++ & - \\
NH3 & + & +++ & +++ & ++ & +++ \\
NH4 & + & ++ & ++ & ++ & \pm \\
NH5 & + & ++ & ++ & ++ & \pm \\
YFPN & & + & + & + & \pm \\
\hline
\end{tabular}

Rice NH proteins are fused to YFPN and TGA proteins fused to YFPC. Interactions between the two families were tested. Other criteria are as described in Table 3.

Instead, it appeared to decrease the background signal observed for rTGA2.1, rTGA2.3, rLG2, TGAL2, and TGAL4. These results suggest that NH4 and NH5 may interact with $\mathrm{RH} 2$ or these TGA proteins, but neither forms a complex containing RH2 and any of these TGA proteins. When $\mathrm{NH} 4$ or $\mathrm{NH} 5$ was ectopically expressed, it interrupted the interaction between RH2 and rTGA2.1, rTGA2.3, rLG2, TGAL2, or TGAL4, and possibly NH3.

When YFPC-fused RH3 was co-introduced with YFPNfused TGA proteins, no YFP signals were detected, suggesting that these proteins do not interact with each other in protoplasts under our experimental conditions. When these combinations were tested with the addition of $\mathrm{NH}$ family members, 13 positive interactions were detected from 36 combinations. Ectopic introduction of $\mathrm{NH} 1$ resulted in strong YFP signals from all six TGA proteins, suggesting that $\mathrm{NH} 1$ can form a complex containing RH3 and any of the six TGA proteins. Introduction of NH2 also led to strong YFP signals from rTGA2.1, rTGA2.2, rTGA2.3, and TGAL2, and a weaker signal from rLG2. Thus, NH2 can form a complex with RH3 and rTGA2.1, rTGA2.2, rTGA2.3, and TGAL2. Introduction of NH3 resulted in weak signal intensity for rTGA2.3 and TGAL4, suggesting that NH3 may form a complex with RH3 and rTGA2.3 or TGAL4, albeit in low abundance. Introduction of $\mathrm{NH} 4$ or $\mathrm{NH} 5$ had no effect on

Table 8 Summary of split YFP results

\begin{tabular}{ccccccc}
\hline & \multicolumn{7}{c}{ YFPC fusion } \\
\cline { 2 - 7 } YFPN fusion & YFPC & NH1 & NH2 & NH3 & NH4 & NH5 \\
\hline NRR & $+_{+}$ & +++ & + & $++_{+}$ & ++ & + \\
RH1 & $+_{+}$ & +++ & + & +++ & ++ & ++ \\
RH2 & + & +++ & - & ++ & ++ & ++ \\
RH3 & + & +++ & + & +++ & $+_{+}$ & \pm \\
YFPN & & \pm & - & \pm & \pm & - \\
\hline
\end{tabular}

Rice $\mathrm{RH}$ proteins are fused to YFPN and NH proteins fused to YFPC. Interactions between the two families were tested. Other criteria are as described in Table 3. 


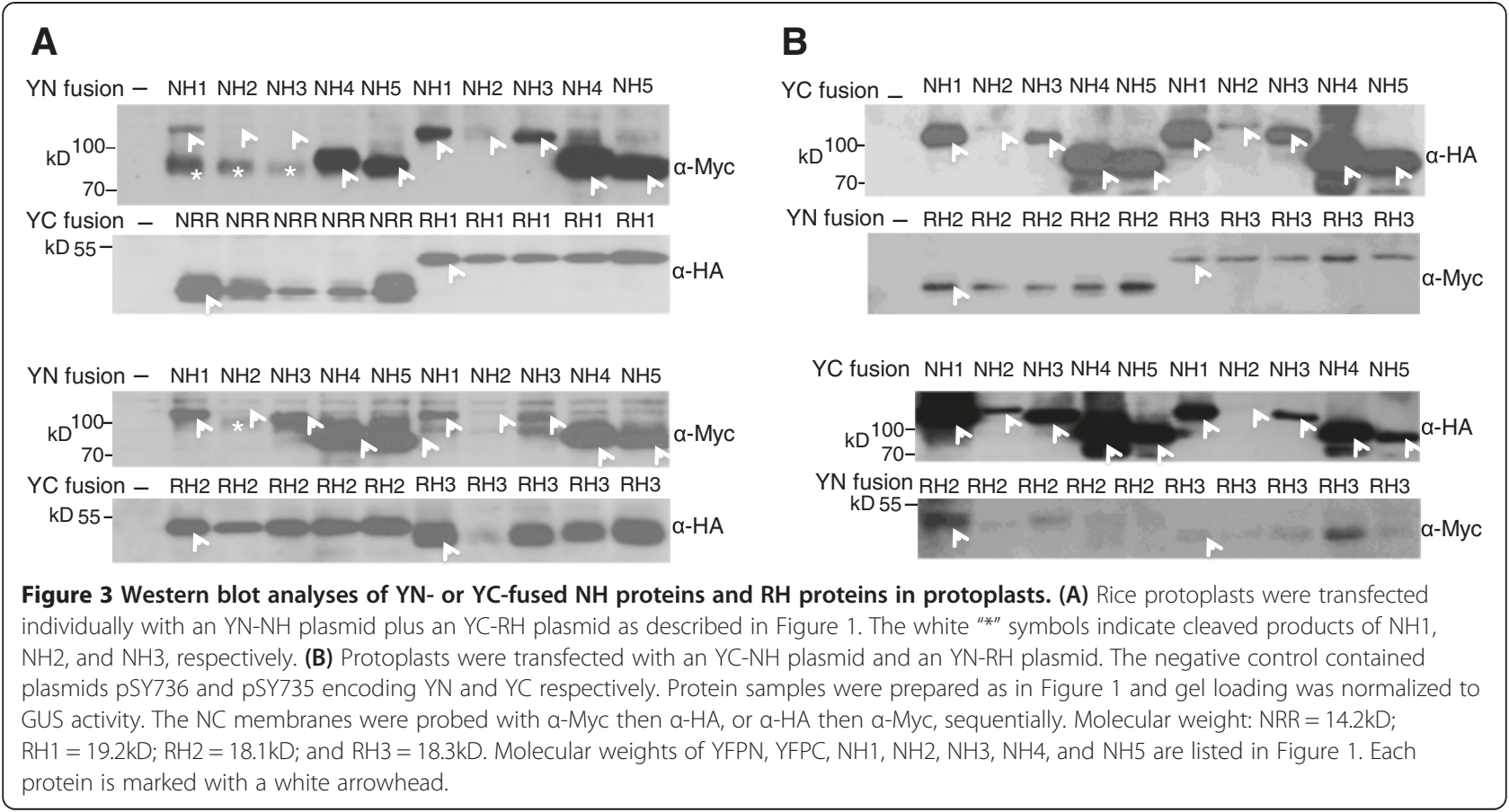

YFP signals, suggesting that NH4 and NH5 may not form complexes with RH3 and these TGA proteins.

Our bridged split YFP data reveals the complexity and specificity of TGA, RH, and NH protein family interactions. A summary of preferred interaction partners

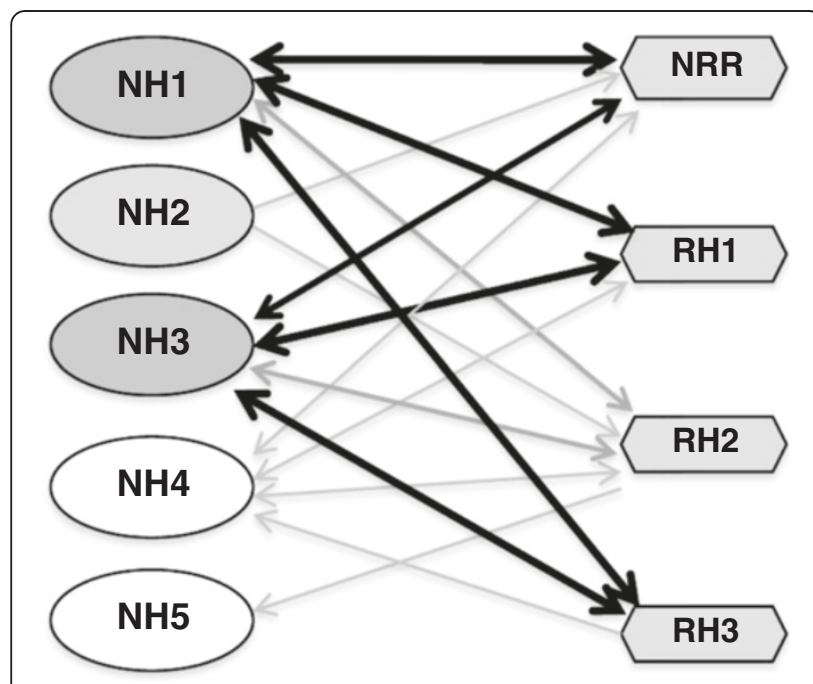

Figure 4 Interaction network between rice $\mathrm{NH}$ and $\mathrm{RH}$ family proteins. The summary is based primarily on split YFP results with $\mathrm{Y} 2 \mathrm{H}$ results taken into consideration. Among the five rice $\mathrm{NH}$ proteins, $\mathrm{NH} 1$ and $\mathrm{NH} 3$ are the major interactors of $\mathrm{RH}$ proteins. $\mathrm{NRR}, \mathrm{RH} 1$, and $\mathrm{RH} 3$ are the major interactors of $\mathrm{NH} 1$ and $\mathrm{NH}$. Strong interactions are shown as solid dark lines and weak interactions are shown as grey lines. Bidirectional arrows indicate that both YFPN and YFPC fusions interact well, while single arrows indicate that only one of the fusions interacts in split YFP. deduced from the bridged split YFP experiments is presented in Figure 5. Figure 5A depicts the TGA and RH proteins that associate with $\mathrm{NH} 1$ and Figure $5 \mathrm{~B}$ shows those that associate with NH3. Both $\mathrm{NH} 1$ and $\mathrm{NH} 3$ interact with rTGA2.1, rTGA2.2, rTGA2.3, rLG2, TGAL2, and TGAL4. NH1 interacts well with all four RH proteins, despite weaker interaction with $\mathrm{RH} 2$, and NH3 interacts well with three RH members, not including RH3. Strong interactions are depicted as solid lines and weak ones as dashed lines. Figure $5 \mathrm{C}$ presents partners of NH2. NH2 also interacts with the six TGA members tested in protoplasts, but only in the presence of $\mathrm{RH} 2$ or RH3. Partners of NH4 and NH5 are depicted in Figure 5D, where NH4 only weakly associates with RH1 and three TGA members: rTGA2.2, rTGA2.3, and TGAL4. NH5 shows weak association with RH1 and TGAL4.

$\mathrm{NH} 3$ is tightly co-expressed with $\mathrm{NH} 1$, consistent with their roles in rice defense responses

Because genes regulating the same pathways are likely to be co-expressed $[47,48]$, we examined the expression of members of the $\mathrm{NH}$ and $\mathrm{RH}$ protein families. We analyzed $\mathrm{NH} 1, \mathrm{NH} 2, \mathrm{NH} 3, \mathrm{NH} 4$, and $\mathrm{NH} 5$ expression levels from 32 publicly available Affymetrix rice microarray data sets covering a broad range of experimental and developmental conditions (conditions listed in Additional file 6: Table S1). We employed a previously reported tool for co-expression analysis [45]. Figure 6 presents the expression coefficient data for each pair of genes. Because $\mathrm{NH} 1$ is the most well known member of rice NPR1-like 
Table 9 Summary of bridged split YFP results

\begin{tabular}{|c|c|c|c|c|c|c|c|c|}
\hline \multirow{2}{*}{ YFPC fusion } & & \multicolumn{7}{|c|}{ YFPN fusion } \\
\hline & & rTGA2.1 & rTGA2.2 & rTGA2.3 & rLG2 & TGAL2 & TGAL4 & YFPN \\
\hline \multirow{5}{*}{ YFPC } & NH1ox & - & - & - & - & - & - & \\
\hline & NH2ox & - & - & - & - & - & - & \\
\hline & NH3ox & - & - & - & - & - & - & \\
\hline & NH4ox & - & - & - & - & - & - & \\
\hline & NH5ox & - & - & - & - & - & - & \\
\hline \multirow{6}{*}{ NRR } & - & - & - & - & - & - & + & \\
\hline & NH1ox & +++ & +++ & +++ & +++ & +++ & +++ & - \\
\hline & NH2ox & \pm & \pm & + & - & \pm & + & - \\
\hline & NH3ox & ++ & ++ & ++ & ++ & ++ & ++ & \pm \\
\hline & NH4ox & - & - & - & - & - & + & - \\
\hline & NH5ox & - & - & - & - & - & \pm & - \\
\hline \multirow{6}{*}{$\mathrm{RH} 1$} & - & - & \pm & \pm & \pm & \pm & + & \\
\hline & NH1ox & +++ & +++ & +++ & +++ & +++ & +++ & \pm \\
\hline & $\mathrm{NH} 2 \mathrm{ox}$ & \pm & \pm & \pm & - & + & + & - \\
\hline & NH3ox & +++ & +++ & +++ & $++/+$ & +++ & +++ & \pm \\
\hline & NH4ox & \pm & + & + & \pm & \pm & + & - \\
\hline & NH5ox & - & - & \pm & - & \pm & + & - \\
\hline \multirow{6}{*}{$\mathrm{RH} 2$} & - & \pm & - & - & + & + & $+/++$ & \\
\hline & NH1ox & + & + & ++ & + & +++ & ++ & - \\
\hline & NH2ox & ++ & +++ & +++ & ++ & +++ & ++ & - \\
\hline & NH3ox & +++ & ++ & +++ & +++ & +++ & +++ & - \\
\hline & NH4ox & \pm & \pm & \pm & \pm & \pm & \pm & - \\
\hline & NH5ox & - & - & - & - & - & - & - \\
\hline \multirow{6}{*}{$\mathrm{RH} 3$} & - & - & - & - & - & - & - & \\
\hline & NH1ox & +++ & +++ & +++ & +++ & +++ & +++ & - \\
\hline & NH2ox & +++ & +++ & +++ & + & +++ & - & - \\
\hline & NH3ox & - & - & + & - & \pm & + & - \\
\hline & NH4ox & - & - & - & - & - & - & - \\
\hline & NH5ox & - & - & - & - & - & - & - \\
\hline
\end{tabular}

Rice TGA proteins are fused to YFPN and RH proteins fused to YFPC. Each NH protein was co-introduced with the YFPN and YFPC fusion proteins into protoplasts. Indirect interaction between a TGA and a RH protein, bridged by a NH protein, reconstitutes YFP fluorescence. Semi-quantitative results were recorded. Bright YFP fluorescence are shown as" +++ " and lack of YFP fluorescence indicated as "-".

proteins involved in biotic stress responses, we used $\mathrm{NH} 1$ as the reference for comparison with other members of the same family. When an expression coefficient of $\geq 0.5$ (highlighted in purple) was set for positive correlation and a coefficient of $\leq-0.5$ (highlighted in light blue) was set for inverse correlation, $\mathrm{NH} 2$ showed seven positive correlations and three inverse correlations out of the 32 sets of data examined. When the same data sets were probed for $\mathrm{NH} 1$ and $\mathrm{NH} 3$ expression correlation, however, 13 positive correlations and one inverse correlation were determined, suggesting that the expression of these two genes is strongly linked. In comparison with NH1, NH4 yielded 3 positive correlations and and one inverse correlation, and NH5 had 3 positive correlations and 6 inverse correlations. Thus, among the NPR1-like genes, NH3 expression is most closely associated with $\mathrm{NH} 1$ expression.

We also examined whether other members of the $\mathrm{NH}$ family demonstrated strong co-expression profiles. When $\mathrm{NH} 3$ expression was used as the reference for $\mathrm{NH} 2,17$ positive correlations and one inverse correlation were determined. NH3 and NH4 showed 10 positive correlations and no inverse correlations, while $\mathrm{NH} 5$ had 3 positive correlations and only one inverse correlation with $\mathrm{NH} 3$ expression. These data suggest that $\mathrm{NH} 2$ and $\mathrm{NH} 3$ expression are highly correlated, which is consistent 

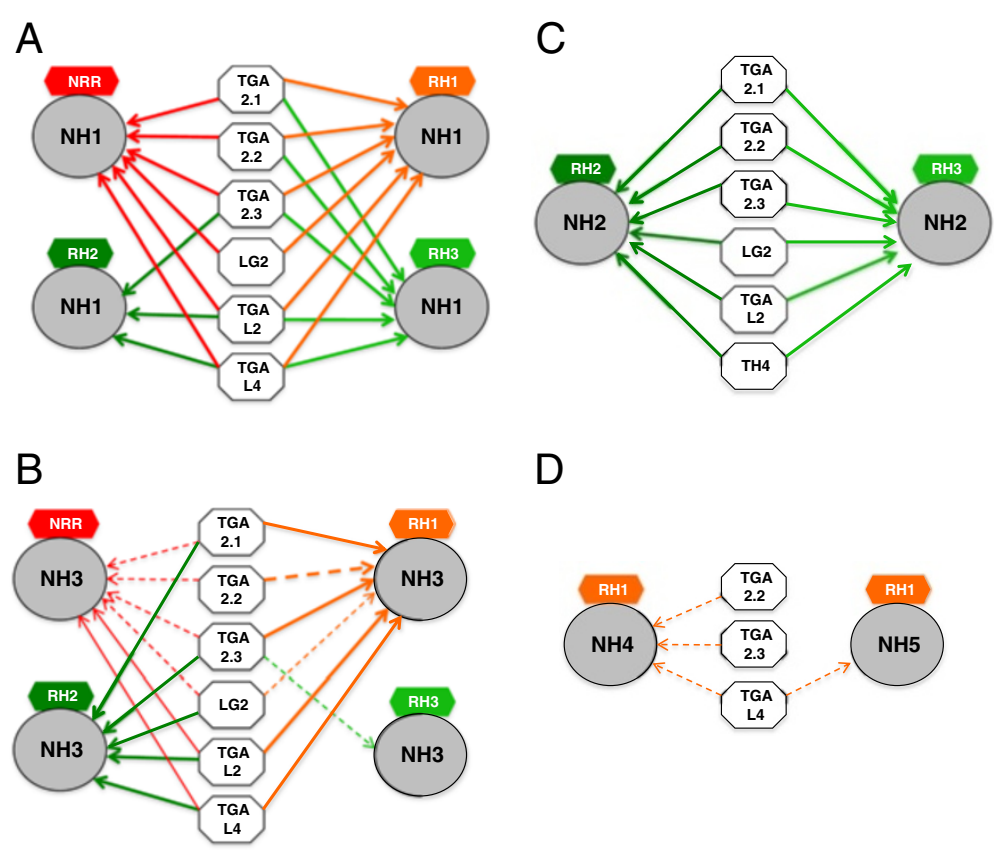

D

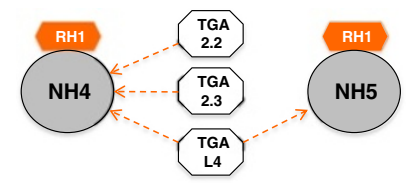

Figure 5 A schematic representation of TGA, NH, and $\mathrm{RH}$ protein complexes. The array of protein complexes is deduced from the bridged split YFP results. (A) NH1-mediated protein complexes. (B) NH3- mediated protein complexes. (C) NH2- mediated protein complexes. (D) NH4- and $\mathrm{NH} 5$ - mediated protein complexes. The arrows are colored according to the RH protein that associates with the selected NH protein. Solid lines suggest strong associations while dashed lines indicate weak ones.

with our previous report that $\mathrm{NH} 2$ and $\mathrm{NH} 3$ are members of the same clade within the NH family [24]. NH3 and $\mathrm{NH} 4$ expression are also highly correlated, suggesting that $\mathrm{NH} 3$ may also work with NH4 under certain conditions. When NH4 and NH5 expression were compared, 16 positive correlations and only one inverse correlation were detected. These data are consistent with our previous report, which showed that $\mathrm{NH} 4$ and $\mathrm{NH} 5$ are most closely related to one another and form a single clade and are involved in plant development, rather than biotic stress responses [24].

In summary, our co-expression analyses suggest that among the rice NPR1-like homologs, NH3 expression is most closely correlated with that of $\mathrm{NH} 1$, consistent with our previous reports showing that both $\mathrm{NH} 1$ and $\mathrm{NH} 3$ contribute to rice defense responses. NH3 also shows a high degree of co-expression with $\mathrm{NH} 2$ and $\mathrm{NH} 4$, demonstrating that it is a versatile protein with a number of potential roles in defense and development.

\section{$\mathrm{NH} 3$ is most highly co-expressed with $\mathrm{RH} 1$ and $\mathrm{RH} 2$}

Using the aforementioned criteria, we also analyzed the expression coefficients between $\mathrm{NH}$ family members and RH family members to assess which members have overlapping expression profiles (Figure 7). Most strikingly, NH3 was most highly co-expressed with RH1, showing 24 positive correlations and no inverse correlations out of the 32 data sets analyzed. NH3 was also highly co-expressed with $\mathrm{RH} 2$ and $\mathrm{RH} 3$, displaying 14 positive correlations and one inverse correlation and 10 positive correlations and two inverse correlations, respectively. NRR showed little co-expression with $\mathrm{NH} 3$, having three positive correlations and two negative ones.

Other members of the $\mathrm{NH}$ family also showed a significant overlap in expression with members of the $\mathrm{RH}$ family. NH2 showed high co-expression with RH1 (13 positive and no inverse correlations) and RH3 (14 positive and 3 inverse correlations). $\mathrm{NH} 2$ also showed modest co-expression with RH2 (8 positive and 2 inverse correlations) and with NRR (7 positive and 2 inverse correlations). NH1, however, showed much lower positive co-expression with NRR, RH1, RH2, and $\mathrm{RH} 3$ than either $\mathrm{NH} 2$ or NH3, yet $\mathrm{NH} 1$ showed a notably higher degree of inverse correlation with these genes $(6,5,10$, and 5 inverse correlations, respectively). Finally, NH4 showed a modest correlation with RH1 (6 positive and 2 inverse correlations), while NH5 displayed a very low degree of correlation with NRR (4 inverse correlations), $\mathrm{RH} 2$ (5 positive and one inverse correlations), and RH3 (4 positive and 6 inverse correlations).

These results suggest that of the genes present in these two families, the function of NH3 is the most positively associated with RH1 and RH2. Conversely, NH1 function is the most negatively correlated with $\mathrm{RH}$ family 


\begin{tabular}{|c|c|c|c|c|c|c|c|c|c|c|c|}
\hline \multirow[b]{2}{*}{ No. } & \multirow[b]{2}{*}{ Experiments } & NH1 & NH1 & NH1 & NH1 & $\mathrm{NH} 2$ & $\mathrm{NH} 2$ & NH2 & NH4 & $\mathrm{NH} 3$ & NH4 \\
\hline & & NH2 & NH3 & NH4 & NH5 & NH3 & NH4 & NH5 & NH3 & NH5 & NH5 \\
\hline 1 & E-MEXP-1766 & -0.582 & -0.261 & 0.828 & 0.818 & 0.777 & -0.790 & -0.771 & -0.332 & -0.328 & 0.966 \\
\hline 2 & E-MEXP-2401 & 0.247 & 0.814 & 0.402 & -0.091 & -0.213 & -0.579 & -0.793 & 0.723 & 0.395 & 0.776 \\
\hline 3 & E-MEXP-2506 & -0.133 & 0.337 & -0.252 & -0.551 & 0.555 & -0.197 & -0.192 & -0.141 & -0.396 & 0.493 \\
\hline 4 & E-MTAB-275 & -0.134 & 0.073 & 0.429 & 0.323 & 0.500 & -0.234 & 0.029 & 0.296 & -0.003 & 0.234 \\
\hline 5 & GSE10373 & 0.293 & 0.666 & 0.054 & 0.123 & 0.441 & -0.042 & -0.365 & -0.094 & 0.058 & 0.303 \\
\hline 6 & GSE10857 & -0.010 & 0.652 & -0.185 & -0.050 & 0.118 & 0.038 & 0.630 & -0.010 & 0.161 & 0.300 \\
\hline 7 & GSE11025 & 0.626 & 0.025 & -0.452 & -0.356 & 0.312 & -0.387 & -0.150 & -0.546 & -0.445 & 0.701 \\
\hline 8 & GSE12069 & 0.384 & 0.504 & 0.639 & -0.060 & 0.858 & 0.364 & 0.443 & 0.594 & 0.548 & 0.412 \\
\hline 9 & GSE13988 & -0.065 & -0.399 & -0.103 & -0.324 & 0.711 & 0.500 & 0.289 & 0.408 & 0.323 & 0.543 \\
\hline 10 & GSE14298 & -0.665 & 0.666 & 0.581 & -0.880 & -0.137 & -0.068 & 0.403 & 0.803 & -0.834 & -0.592 \\
\hline 11 & GSE14299 & 0.300 & 0.514 & 0.473 & 0.598 & 0.541 & 0.222 & 0.020 & 0.679 & 0.627 & 0.562 \\
\hline 12 & GSE14300 & -0.184 & -0.128 & -0.305 & -0.357 & 0.914 & 0.637 & 0.077 & 0.686 & 0.250 & 0.657 \\
\hline 13 & GSE14403 & 0.609 & 0.874 & -0.177 & -0.182 & 0.656 & -0.337 & -0.251 & -0.340 & 0.006 & -0.198 \\
\hline 14 & GSE1 & 0.852 & 0.150 & 0.172 & 0.404 & 0.403 & 0.106 & 0.253 & -0.468 & -0.308 & 0.720 \\
\hline 15 & GSE15046 & 0.626 & 0.641 & 0.050 & -0.515 & 0.976 & 0.529 & 37 & 0.575 & 0.178 & 0.679 \\
\hline 16 & GSE15071 & 0.350 & 0.369 & -0.519 & -0.548 & 0.186 & -0.688 & -0.508 & 0.023 & -0.358 & 0.659 \\
\hline 17 & GSE16108 & -0.144 & 0.035 & 0.121 & 0.047 & -0.582 & -0.453 & -0.053 & 0.307 & 0.143 & 0.679 \\
\hline 18 & GSE16341 & -0.023 & -0.143 & -0.346 & -0.144 & 0.690 & 0.886 & 0.846 & 0.632 & 0.508 & 0.868 \\
\hline 19 & GSE16793 & 0.303 & 0.375 & -0.082 & -0.237 & 0.388 & -0.183 & -0.379 & -0.360 & -0.390 & 0.645 \\
\hline 20 & GSE17245 & 0.233 & 0.530 & 0.455 & 0.218 & 0.635 & 0.218 & -0.266 & 0.201 & -0.174 & 0.157 \\
\hline 21 & GSE18361 & 0.670 & 0.634 & -0.187 & 0.220 & 0.913 & 0.426 & -0.191 & 0.523 & -0.193 & -0.681 \\
\hline 22 & GSE19024 & 0.217 & 0.004 & -0.059 & -0.071 & 0.371 & -0.234 & -0.010 & -0.130 & -0.137 & 0.198 \\
\hline 23 & GSE19239 & -0.376 & -0.417 & 0.139 & -0.529 & 0.726 & -0.399 & 0.458 & -0.223 & 0.380 & -0.378 \\
\hline 24 & GSE24048 & 0.847 & 0.914 & 0.396 & 0.543 & 0.894 & 0.612 & 0.521 & 0.571 & 0.458 & 0.078 \\
\hline 25 & GSE24228 & 0.234 & 0.280 & -0.336 & -0.228 & -0.102 & -0.651 & -0.686 & -0.143 & -0.031 & 0.762 \\
\hline 26 & GSE25206 & 0.249 & 0.329 & -0.222 & 0.048 & 0.523 & -0.415 & -0.106 & -0.397 & -0.487 & 0.781 \\
\hline 27 & GSE26280 & 0.162 & 0.575 & 0.470 & 0.057 & 0.267 & 0.332 & 0.210 & 0.710 & 0.247 & 0.147 \\
\hline 28 & GSE4471 & -0.652 & -0.030 & 0.318 & 0.171 & 0.628 & -0.371 & -0.321 & -0.368 & -0.392 & 0.126 \\
\hline 29 & GSE6737 & -0.266 & -0.308 & -0.623 & -0.732 & 0.731 & 0.748 & 0.035 & 0.310 & 0.002 & 0.455 \\
\hline 30 & GSE6893 & 0.484 & 0.605 & 0.494 & 0.264 & 0.732 & 0.208 & -0.088 & 0.385 & 0.278 & 0.748 \\
\hline 31 & GSE6901 & 0.657 & -0.845 & -0.349 & -0.371 & -0.381 & -0.579 & -0.836 & 0.220 & 0.154 & 0.683 \\
\hline 32 & os4 & -0.488 & 0.240 & 0.389 & -0.299 & -0.050 & -0.053 & 0.229 & 0.019 & 0.350 & -0.442 \\
\hline
\end{tabular}

Figure 6 Expression coefficient of rice NPR1-like members under various experimental conditions. The expression coefficients equal to or higher than 0.5 are highlighted in purple and those equal to or lower than -0.5 in blue. 


\begin{tabular}{|c|c|c|c|c|c|c|c|c|c|c|c|c|c|c|c|c|c|c|c|c|c|}
\hline & Experi & NRR & $\mathrm{NH} 1$ & NH1 & NH1 & NRR & NH2 & $\mathrm{HH} 2$ & RH3 & NRR & NH3 & RH2 & RH3 & NRR & NH4 & RH2 & RH3 & NRR & RH1 & RH2 & RH3 \\
\hline No. & o. ments & NH1 & RH1 & RH2 & RH3 & NH2 & RH1 & NH2 & $\mathrm{NH} 2$ & NH3 & RH1 & NH3 & NH3 & NH4 & RH1 & NH4 & NH4 & NH5 & NH5 & NH5 & NH5 \\
\hline 1 & \begin{tabular}{|l|} 
E-MEXP- \\
1766
\end{tabular} & -0.438 & 653 & 0.241 & 595 & 0.013 & 0.901 & 369 & 0.920 & .177 & 0.606 & -0.354 & 40.848 & -0.235 & -0.895 & 0.161 & -0.707 & -0.290 & -0.897 & 0.291 & -0.671 \\
\hline 2 & \begin{tabular}{|l|} 
E-MEXP- \\
2401
\end{tabular} & 0.440 & 795 & 681 & .792 & 0.134 & 174 & .351 & -0.477 & 0.422 & 0.891 & 0.880 & -0.418 & 0.453 & $.543 c$ & 0.811 & 0.030 & 0.106 & 0.124 & 0.587 & 0.540 \\
\hline 3 & \begin{tabular}{|l|} 
E-MEXP- \\
2506
\end{tabular} & -0.068 & 0.326 & -0.088 & -0.043 & $3-0.035$ & -0.052 & .021 & -0.045 & 0.113 & 0.592 & 0.259 & 0.214 & 0.182 & 0.150 & 0.100 & 0.194 & -0.030 & -0.313 & $-0.079 \mid$ & 0.042 \\
\hline 4 & \begin{tabular}{|l|} 
E-MTAB- \\
275
\end{tabular} & -0.570 & -0.092 & -0.441 & 111 & 0.419 & 0.189 & 480 & 0.160 & 0.203 & 0.568 & 0.531 & 0.482 & -0.470 & $0.421 \mid c$ & 0.028 & 0.532 & -0.382 & -0.099 & 0.002 & 0.244 \\
\hline 5 & \begin{tabular}{|l|} 
GSE1037 \\
3
\end{tabular} & 70.226 & 513 & 0.631 & 599 & 0.165 & 0.118 & 299 & 0.536 & 0.043 & 0.788 & 0.796 & 0.705 & 0.050 & .223 & -0.108 & -0.138 & -0.160 & 0.050 & 0.154 & -0.185 \\
\hline 6 & \begin{tabular}{|l|} 
GSE1085 \\
7
\end{tabular} & 0.057 & 0.426 & 0.086 & -0.167 & 0.205 & 0.529 & 0.804 & 0.630 & 0.216 & 0.656 & 0.362 & 0.026 & -0.205 & 0.172 & 0.197 & 0.072 & 0.101 & 0.380 & 0.715 & 0.552 \\
\hline 7 & \begin{tabular}{|l|} 
GSE1102 \\
5
\end{tabular} & 0.533 & -0.482 & -0.507 & 606 & 0.573 & -0.239 & 995 & -0.302 & 157 & 0.529 & 0.365 & 0.209 & 0.106 & .122 & 0.395 & 0.138 & 0.299 & 0.065 & 0.473 & 0.030 \\
\hline 8 & \begin{tabular}{|l|} 
GSE1206 \\
9
\end{tabular} & -0.056 & 0.531 & -0.179 & 0.497 & -0.196 & 50.298 & 493 & 0.653 & -0.066 & 0.621 & 0.158 & 0.905 & 0.193 & 0.399 & -0.045 & 0.585 & 0.072 & 0.020 & 0.481 & 0.360 \\
\hline 9 & \begin{tabular}{|l|} 
GSE1398 \\
8
\end{tabular} & 8.244 & 0.156 & -0.259 & -0.283 & 0.603 & 0.640 & .707 & 0.790 & 0.177 & 0.416 & 0.722 & 0.771 & 0.252 & 0.479 & 0.209 & 0.487 & -0.036 & 0.412 & 0.120 & 0.179 \\
\hline 10 & \begin{tabular}{|l|} 
GSE1429 \\
8
\end{tabular} & 9 & 361 & 676 & .462 & 0.510 & 0.509 & 584 & 0.605 & 0.448 & 0.304 & -0.039 & 0.167 & 0.202 & 272 & -0.2 & 0.081 & -0.100 & 0.186 & 0.364 & 0.198 \\
\hline 11 & $\begin{array}{l}\text { GSE1429 } \\
9\end{array}$ & $\begin{array}{l}9.135 \\
\end{array}$ & -0.422 & -0.518 & $-0.297 \mid$ & 0.598 & 0.272 & .052 & 0.540 & 0.289 & 0.176 & 0.078 & 0.103 & 0.077 & -0.235 & 0.048 & -0.256 & -0.140 & -0.116 & $-0.138 \mid$ & -0.301 \\
\hline 12 & \begin{tabular}{|l|} 
GSE1430 \\
0
\end{tabular} & 0.352 & -0.095 & 0.098 & 0.288 & 0.052 & 0.844 & 0.805 & 0.564 & 0.147 & 0.945 & 0.885 & 0.555 & -0.093 & 0.729 & 0.758 & 0.529 & -0.163 & 0.310 & 0.368 & 0.156 \\
\hline 13 & \begin{tabular}{|l} 
GSE1440 \\
3
\end{tabular} & 0 & 591 & 0.140 & 321 & 0.337 & 0.085 & .026 & -0.025 & 001 & 0.626 & 0.229 & 0.255 & 0.010 & -0.156 & 0.129 & 0.310 & -0.511 & 0.119 & -0.265 & -0.259 \\
\hline 14 & $\begin{array}{l}\text { GSE1469 } \\
2\end{array}$ & 9.539 & -0.101 & -0.797 & -0.369 & -0.284 & 40.221 & .587 & -0.038 & 0.005 & 0.818 & -0.004 & 40.292 & -0.098 & -0.557 & $-0.097 \mid$ & -0.384 & -0.428 & -0.352 & $-0.200 \mid$ & -0.363 \\
\hline 15 & \begin{tabular}{|l|} 
GSE1504 \\
6
\end{tabular} & \begin{tabular}{l|l}
4 & -0.687 \\
\end{tabular} & -0.044 & -0.691 & -0.126 & -0.332 & 0.737 & .010 & 0.601 & -0.415 & 0.694 & -0.093 & 0.504 & 0.014 & 0.562 & 0.220 & 0.404 & 0.396 & 0.533 & 0.679 & 0.544 \\
\hline 16 & \begin{tabular}{|l|} 
GSE1507 \\
1
\end{tabular} & & .709 & 0.115 & 212 & -0.534 & $4 \mid-0.388$ & .018 & -0.278 & .283 & .107 & -0.519 & $9-0.419$ & 0.528 & 0.671 & -0.154 & 0.068 & 0.259 & 0.418 & 0.376 & -0.050 \\
\hline 17 & \begin{tabular}{|l|} 
GSE1610 \\
8
\end{tabular} & -0.131 & -0.185 & -0.248 & .174 & 0.355 & 0.272 & .327 & 0.714 & -0.651 & -0.084 & 0.582 & -0.523 & -0.271 & 0.402 & 0.303 & -0.159 & -0.301 & 0.606 & 0.258 & 0.046 \\
\hline 18 & \begin{tabular}{|l|} 
GSE1634 \\
1
\end{tabular} & \begin{tabular}{|l|l|}
4 & -0.211 \\
\end{tabular} & .557 & -0.699 & 209 & -0.776 & 50.499 & -0.208 & -0.792 & -0.246 & 0.644 & 0.227 & -0.496 & -0.615 & 0.562 & 0.071 & -0.727 & -0.709 & 0.364 & $-0.177 \mid$ & -0.693 \\
\hline 19 & \begin{tabular}{|l|} 
GSE1679 \\
3
\end{tabular} & 9.048 & 0.503 & 0.104 & 0.183 & -0.027 & 0.080 & .174 & 0.239 & 0.147 & 0.585 & 0.453 & 0.334 & 0.073 & 0.051 & 0.000 & 0.101 & 0.036 & 0.067 & 0.073 & 0.114 \\
\hline 20 & \begin{tabular}{|l|} 
GSE1724 \\
5
\end{tabular} & 0.014 & 0.271 & 0.088 & .351 & 0.108 & 0.584 & 217 & -0.064 & -0.063 & 0.677 & 0.204 & -0.202 & 0.305 & 0.023 & -0.271 & -0.712 & -0.021 & -0.266 & -0.190 & -0.409 \\
\hline 21 & \begin{tabular}{|l|} 
GSE1836 \\
1
\end{tabular} & 6 & 354 & 0.286 & 121 & -0.154 & 40.869 & 721 & 0.728 & 0.119 & 0.873 & 0.768 & 0.734 & 0.559 & .590 & 0.683 & 0.801 & -0.654 & -0.337 & -0.669 & -0.567 \\
\hline 22 & \begin{tabular}{|l|} 
GSE1902 \\
4
\end{tabular} & \begin{tabular}{|l}
2 \\
\end{tabular} & .157 & -0.106 & .000 & -0.015 & 50.077 & 0.193 & 0.257 & 0.095 & 0.380 & 0.217 & 0.193 & -0.024 & 0.063 & -0.108 & -0.036 & 0.160 & -0.230 & -0.269 & -0.118 \\
\hline 23 & \begin{tabular}{|l|} 
GSE1923 \\
9
\end{tabular} & 0.263 & -0.629 & -0.522 & 288 & -0.311 & 10.519 & 333 & 0.662 & 0.043 & 0.761 & 0.629 & 0.567 & 0.576 & 0140 & 0.342 & -0.633 & -0.434 & 0.246 & -0.100 & 0.608 \\
\hline 24 & \begin{tabular}{|l|} 
GSE2404 \\
8
\end{tabular} & 40.588 & 0.633 & 0.766 & -0.548 & 30.265 & 0.308 & 0.781 & -0.607 & 0.420 & 0.562 & 0.699 & -0.535 & 0.118 & $0.144 \mathrm{C}$ & 0.404 & 0.106 & 0.300 & 0.398 & 0.476 & -0.582 \\
\hline 25 & \begin{tabular}{|l|} 
GSE2422 \\
8
\end{tabular} & \begin{tabular}{|l|l|}
2 & -0.294 \\
\end{tabular} & .078 & 0.169 & 0.294 & -0.293 & $3 \mid-0.069$ & .357 & -0.536 & 517 & 0.146 & -0.162 & 0.138 & 0.129 & .3030 & 0.003 & 0.143 & 0.216 & -0.202 & -0.065 & 0.221 \\
\hline 26 & \begin{tabular}{|l|} 
GSE2520 \\
6
\end{tabular} & 0.251 & 025 & 29 & 199 & 0.595 & 0.701 & 776 & 10 & 0.826 & 0.710 & 0.685 & 0.802 & -0.336 & 016 & -0.127 & -0.225 & -0.413 & -0.077 & $-0.196 \mid$ & -0.485 \\
\hline 27 & \begin{tabular}{|l|} 
GSE2628 \\
0
\end{tabular} & $\begin{array}{ll}8 & 0.227\end{array}$ & 0.220 & 0.183 & .548 & 0.148 & 0.316 & 0.414 & -0.259 & 0.572 & 0.580 & 0.563 & -0.240 & 0.349 & 0.441 & 0.498 & -0.243 & 0.261 & 0.373 & 0.494 & -0.015 \\
\hline 28 & GSE4471 & 0.552 & -0.516 & -0.224 & -0.422 & 0.118 & 0.948 & 0.843 & 0.867 & 0.450 & 0.658 & 0.802 & 0.650 & 0.293 & 0.294 & -0.180 & -0.047 & 0.144 & -0.437 & -0.262 & -0.355 \\
\hline 29 & GSE6737 & $7-0.635$ & -0.471 & -0.709 & 0.080 & 0.730 & 0.639 & 0.135 & -0.211 & 0.550 & 0.861 & 0.514 & 0.351 & 0.750 & $0.409 \mathrm{C}$ & 0.192 & -0.460 & 0.404 & 0.281 & 0.538 & 0.008 \\
\hline 30 & GSE6893 & 30.150 & 0.594 & 0.066 & 0.149 & 0.323 & 0.762 & -0.062 & 0.656 & 0.479 & 0.840 & 0.098 & 0.376 & -0.018 & $0.338 \mathrm{C}$ & 0.008 & -0.441 & 0.244 & 0.119 & 0.077 & 0.640 \\
\hline 31 & GSE6901 & 10.666 & 465 & -0.789 & 0.034 & 45 & 0.186 & -0.697 & 0.257 & -0.431 & 740 & 0.747 & -0.010 & -0.572 & $-0.269 \mathrm{C}$ & 0.603 & -0.392 & -0.716 & 441 & 683 & .644 \\
\hline 32 & OS4 & -0.696 & -0.197 & -0.640 & -0.268 & 0.280 & 0.233 & 0.461 & -0.130 & -0.370 & 0.423 & -0.033 & 0.316 & -0.448 & -0.268 & -0.411 & -0.162 & 0.196 & 0.488 & 0.303 & 0.290 \\
\hline
\end{tabular}

Figure 7 Expression coefficient between rice NH1 members and NRR members under various experimental conditions. The expression coefficients equal to or higher than 0.5 are highlighted in purple and those equal to or lower than -0.5 in blue. 
members. These expression results represent a major difference between $\mathrm{NH} 1$ and $\mathrm{NH} 3$ expression patterns and suggest that the $\mathrm{RH}$ proteins may differentially modulate $\mathrm{NH} 1$ and $\mathrm{NH} 3$ functions under different conditions.

We also examined co-expression patterns between $\mathrm{NH}$ and rice TGA genes. However, no clear trends were observed and thus are not shown or discussed here.

\section{Discussion}

Yeast two hybrid assays have been widely used to investigate interaction networks among a large number of proteins $[40,41]$. For example, Mukhtar et al. surveyed approximately 8552 proteins and found 1358 interactions among 926 proteins, including 83 microbial effectors, 170 immune proteins, and 673 other Arabidopsis proteins [40]. One drawback to large-scale $\mathrm{Y} 2 \mathrm{H}$ assays, however, is that due to the possible occurrence of false positive interactions, independent in vivo approaches are needed to validate their biological relevance. For example, the validation rates of $\mathrm{Y} 2 \mathrm{H}$-based interactions described on the Arabidopsis Interactome version 1 main screen were about $80 \%$ of the original number identified [41]. However, it is usually impossible to verify all of the results with another independent approach, such as co-immunoprecipitation, considering the amount of labor involved. Yet efforts towards this end have been made; a rice kinase protein interaction map containing 116 representative rice kinases and 254 of their interacting proteins was previously reported [42]. In this study, the rate of overlapping interactions identified by $\mathrm{Y} 2 \mathrm{H}$ and by TAP tag (tandem affinity purification tag)-based co-immunoprecipitation coupled with mass-spectrometry was low-only four interactors overlapped among the 254 identified by the two methods [42]. This low rate of overlap is not unique to this study. Similarly, a low (7\%) rate of overlap was found in the yeast proteome when $\mathrm{Y} 2 \mathrm{H}$ data sets were compared with protein complex data sets generated by TAP tag-based co-immunoprecipitation [49]. In contrast, the results from our split YFP and $\mathrm{Y} 2 \mathrm{H}$ experiments indicate that they generally agree, with overlapping interaction rates between $70 \%$ and $90 \%$, rates considerably higher than those observed when co-immunoprecipitation experiments are used for validating $\mathrm{Y} 2 \mathrm{H}$ interactions. In general, split YFP assays in protoplasts reveal a higher selectivity for interaction partners than the $\mathrm{Y} 2 \mathrm{H}$ assay and are an efficient in vivo method to verify $\mathrm{Y} 2 \mathrm{H}$ results.

For the two halves of split YFP to reconstitute a functional YFP and give fluorescence signals, the two fusion proteins need to be expressed and accumulate in the same cell types and same cellular compartments. The YFPN and YFPC polypeptides need to be proximal to each other enough to form a functional YFP protein. These requirements are not needed for yeast two hybrid assays to work. Thus, in theory and in practice, split YFP assays integrate cellular conditions and are more stringent than yeast two-hybrid assays. Our conclusions are mainly drawn from split YFP results. The discrepancies that occur when different halves of YFP were fused to the protein may be due to interferences when YFPN or YFPC was fused to the test protein, leading to false negatives. In view of this, positive results may be taken over negative results in split YFP assays.

Our survey of the protein-protein interactions between rice $\mathrm{NH}$, TGA, and $\mathrm{RH}$ families reveals a broad, complex interaction network among these three families of proteins and allows us to draw important conclusions. First of all, each rice $\mathrm{NH}$ protein can partner with several different rice TGA and $\mathrm{RH}$ proteins. Second, these $\mathrm{NH}$ proteins show distinct preferences in interaction partners, indicating that while complexes formed by these proteins appear heterogeneous in nature, certain combinations of $\mathrm{NH}, \mathrm{RH}$, and TGA proteins are more likely to occur than others. And finally, members of the $\mathrm{NH}$ family cluster according to their interaction profiles with different TGA and $\mathrm{RH}$ proteins. NH1, NH2, and NH3 form a cluster, while NH4 and NH5 form another cluster. Within the $\mathrm{NH} 1, \mathrm{NH} 2$ and $\mathrm{NH} 3$ cluster, $\mathrm{NH} 1$ and $\mathrm{NH} 3$ interaction profiles are more closely related to each other with regard to their abilities to interact with rice TGA and RH proteins. These results are consistent with our previous finding that $\mathrm{NH} 1$ and $\mathrm{NH} 3$ are the only members of the rice NPR1-like protein family to enhance resistance to Xoo [24]. Other rice NH proteins failed to show positive regulatory effects on immune responses [23].

The immune response-enhancing effects of NH1 and NH3 may be associated with their ability to interact strongly with the same subgroup of rice TGA proteins: rTGA2.1, rTGA2.2, rTGA2.3, rLG2, TGAL2, and TGAL4. Thus, our study on the interaction network of the three families of innate immune regulators may have revealed an important clue as to why $\mathrm{NH} 1$ and $\mathrm{NH} 3$ can regulate immune responses to $\mathrm{Xoo}$, whereas the other $\mathrm{NH}$ proteins do not. Moreover, this group of TGA transcription factors may have emerged as important players in immunity. We hypothesize that $\mathrm{NH} 1$ and $\mathrm{NH} 3$ bind to these TGA transcription factors and act as transcriptional co-activators. One approach to test this hypothesis is to assess the ability of $\mathrm{NH} 1$ and $\mathrm{NH} 3$ to activate expression of a reporter gene in the presence of rTGA2.1, rTGA2.2, rTGA2.3, rLG2, TGAL2, or TGAL4, but not the other TGA factors.

Results of the bridged split YFP assay are generally consistent with the direct split YFP results, but appear more selective. For instance, NH1 and NH3 interact strongly with the same six TGA proteins in both the direct and bridged split YFP assay. NH1 and NH3 also 
interact with the four $\mathrm{RH}$ proteins to varying degrees in both the direct and bridged split YFP assays. However, discrepancies do exist. Some combinations of $\mathrm{RH}$ and TGA proteins appear to disrupt interactions observed in the direct split YFP assay between $\mathrm{NH}$ proteins and members of these other two families. For example, NH3 interacts well with RH3 and all six selected TGA proteins in the direct split YFP assay, but not in the bridged split YFP assay, where only rTGA2.3 and TGAL4 show a weak association with $\mathrm{NH} 3$ in the presence of ectopic RH3. This might be due to steric hindrance resulting from the NH3:RH3 interaction, excluding rTGA proteins from binding to the complex, or the vice versa. $\mathrm{NH} 2$ did not show strong interaction with TGA proteins in the direct split YFP assay (Table 3), but does associate strongly with the six selected TGA proteins in the presence of ectopic RH2 or RH3 (Table 9). One possibility is that association of $\mathrm{NH} 2$ with $\mathrm{RH} 2$ or $\mathrm{RH} 3$ may stabilize the $\mathrm{NH} 2$ protein, allowing $\mathrm{NH} 2$ to accumulate and partner with TGA proteins to produce stronger YFP signals in bridged YFP experiments. However, under normal conditions, $\mathrm{RH} 2$ and $\mathrm{RH} 3$ proteins may not be present at levels high enough to have such an obvious effect.

$\mathrm{NH} 4$ and NH5 also showed differences between interaction profiles depending on whether a direct or bridged split YFP assay was used. In direct split YFP assays, NH4 and NH5 interacted modestly with most rice TGA and $\mathrm{RH}$ proteins with few outstanding preferences. However, in the bridged split YFP assay, only rTGA2.2, rTGA2.3, and TGAL4 associated weakly with $\mathrm{NH} 4$ in the presence of RH1. Similarly, only TGAL4 and RH1 shared a weak association when NH5 was present. Formation of protein complexes in the bridged split YFP assay appeared to be more selective. The observation that few members of the subset of TGA and RH proteins tested could form complexes with $\mathrm{NH} 4$ and $\mathrm{NH} 5$ may also contribute to the fact $\mathrm{NH} 4$ and $\mathrm{NH} 5$ are not involved in innate immunity to Xoo. Our Y2H data supports this possible conclusion, in that NH4 and NH5 (orthologs of Arabidopsis BOP1 and BOP2, blade-on-patiole 1 and blade-on-patiole2) interacted strongly with the TGAL proteins that failed to interact with NH1 and NH3: TGAL5, TGAL7, TGAL8, and TGAL9 (Table 2). These results indicate that these TGA proteins may be involved in plant development rather than defense, similar to Arabidopsis BOP1 and BOP2. This hypothesis can be tested via silencing of these TGAL genes. However, silencing of multiple TGAL genes may be necessary to observe clear phenotypes. Because these TGALs likely mediate the functions of $\mathrm{NH} 4$ and NH5, we hypothesize that bop-like developmental phenotypes $[50,51]$ would appear in the silenced lines. The BOP genes have also been suggested to be involved in methyl jasmonate-mediated resistance in Arabidopsis [52], a defense response distinct from the SA-mediated immune response [53]. These results suggest that silencing of these TGAL genes whose products interact with NH4 and NH5 may block jasmonate-induced defense response in rice.

In Arabidopsis, TGA2, TGA5, and TGA6 appear to be functionally redundant. Alterations in NPR1-mediated SAR response after inducer treatment can only be observed in plants knocked out for all three genes [30]. The rice genome encodes at least 15 TGA-like proteins and some of them may also function redundantly. Our protein-protein interaction results point to rTGA2.1, rTGA2.2, rTGA2.3, rLG2, TGAL2, and TGAL4 as the important candidates for mediating $\mathrm{NH} 1$ and $\mathrm{NH} 3$ function. Silencing of these six TGA-encoding genes singly or multiply will help elucidate the involvement of these TGA proteins in the rice immune response.

Finally, co-expression analyses of 32 sets of rice microarray data lead us to the conclusion that of all $\mathrm{NH}$ members, NH3 expression most closely parallels that of NH1, consistent with the above observation that they interact with similar proteins and share common roles in plant immunity. RH1 expression is most positively correlated with NH3 expression, strongly suggesting that these two proteins may function together. This notion is consistent with the $\mathrm{Y} 2 \mathrm{H}$ and split YFP results that show that these two proteins interact strongly with each other-a relationship that is not observed for $\mathrm{RH} 1$ and $\mathrm{NH} 1$. It remains to be determined what role this NH3-RH1 relationship plays in plants. On the other hand, NH1 expression is inversely correlated with expression of $\mathrm{RH}$ proteins. Together these results suggest that RH1, $\mathrm{RH} 2$, and RH3 proteins may work more closely with $\mathrm{NH} 3$ to modulate its function.

We observed that $\mathrm{NH} 2$ and $\mathrm{NH} 3$ RNA expression levels were highly correlated. This should be no surprise because $\mathrm{NH} 2$ and $\mathrm{NH} 3$ proteins are most homologous to each other forming a clade [24]. NH2 and NH3 functions may differ at the protein level because they behave quite differently in their interactions with the TGA and $\mathrm{RH}$ proteins. The same explanation may also apply to explain the fact that $\mathrm{NH} 2$ expression levels were also highly correlated with those of RH1, RH2, and RH3.

\section{Conclusions}

We have surveyed the interaction partners of three families of plant innate immunity regulators using $\mathrm{Y} 2 \mathrm{H}$ and split YFP assays on a genome-wide scale. Between $70-90 \%$ of the time, the $\mathrm{Y} 2 \mathrm{H}$ results agree with the split YFP results, indicating a broad and complex interaction network between members of these protein families. $\mathrm{Y} 2 \mathrm{H}$ results demonstrate the propensity of these proteins to interact with proteins from other families. The split YFP assay in rice protoplasts shows a higher degree of selectivity in interaction partners for 
these proteins, while our bridged adaptation of the split YFP assay shows an even greater stringency in interaction partners among the three families of proteins. The interaction profiles of $\mathrm{NH}, \mathrm{TGA}$, and $\mathrm{RH}$ family members determined by these assays help to explain why $\mathrm{NH} 1$ and $\mathrm{NH} 3$ play important roles in innate immunity, and also point to a subgroup of TGA proteins (rTGA2.1, rTGA2.2, rTGA2.3, rLG2, TGAL2 and TGAL4) that may be more important to innate immunity than other TGA members. Consistent with their shared role in defense, co-expression analyses reveal that $\mathrm{NH} 1$ and $\mathrm{NH} 3$ expression patterns show remarkable overlap. $\mathrm{NH} 3$ and $\mathrm{RH} 1$ are also very tightly coupled in their expression, suggesting an uncharacterized role for RH1 in defense. Unlike NH3, NH1 expression is inversely correlated with expression of $\mathrm{RH}$ proteins, suggesting that $\mathrm{RH}$ proteins may work more closely with $\mathrm{NH} 3$ than with $\mathrm{NH} 1$ to modulate its function.

\section{Methods}

\section{Cloning of CDNAs}

Rice cDNA was synthesized from total RNA isolated from Nipponbare rice leaf tissues using the Trizol reagent (Invitrogen). NH1 cDNA was amplified with primers NH1-ATG (5'CACCATGGAGCCGCCGACCA GCCAC GTC) and NH1-TAP2 (5'AGCAATGGTGTTCATCTCC TTGGT), NH2 cDNA with primers NH2-ATG (5'CACC ATGCCGGCGCGTAGCGCGGTGGT) and NH2-TAP2 (5'CTGTCATTTC TTTGCAACCTTGG), NH3 cDNA with primers NH3-ATG (5'CACCATGGAGACGTCCA CCA TAAGCT) and NH3-TAP3 (5’ACTGCAGATTAG ACTTAACTGCTG), NH4 cDNA with primers NH4ATG (5'CACCATGGAGGAAACCCTCAAGTCGCT) and NH4-TAP2 (5'CCACACCCCC TTTCGTCGTCAG), and NH5 cDNA with primers NH5-ATG (5'CACCATGAG CTCCGAGGACT CGCTCA) and NH5-TAP2 (5'TCAACACGGCTAGTAGAAGAGAAG). Individual cDNA was cloned into the pENTR/D vector and sequence confirmed.

NRR cDNA was amplified with primers NRR-ATG (CACCATGGACGCCACCACCA CCGCCAAG) and NRR-TAP2 (TTACTAGTTGTAATCCGTGAGCACCC GCAT), RH1 cDNA with primers RH1-ATG (CACC ATGGAGGGAGTTGACGTGAAGGC) and mn133-7 (TTCTCGAGCA AATCAAGACTGGCACATG), RH2 cDNA with primers RH2-ATG (CACCATGGAAGC CCGATTGA GCACGGG) and 133H-2 (TTTACTA GTCTCGAGCCTGATTAATTCATCTGGTCAC), and RH3 cDNA with primers RH3-ATG (CACCATGGAT CCCACGATGCCCACTCC) and 133H2-3 (TTTACTA GTCTCGAGACTCATCTGTATGAACTTG). Individual cDNA was cloned into the pENTR/D vector and confirmed by sequence analysis.

rTGA2.1 cDNA was amplified with primers mn1-for (5'CACCGCAGATGCTAGTTCAA GGACTGAC) and mn1-rev (5'CTAGCAAGCCACAGCGAACTCAAA), rT GA2.2 cDNA with primers mn8-for (5'CACCGCAGA TGCTAGTTCGAGGACTGAC) and mn8-rev (5'TTACT CCCGT GGCCTAGCAAGCCA), rTGA2.3 cDNA with primers mn38-for (5'CACCCCCTTTGCTGCAGAGT $\mathrm{T}$ TGATATG) and mn38-rev (5'CTATTCTTTCGGCCGA GCAAGCCA), rLG2 cDNA with primers mn140-for (5'CACCAGCTCTGTGCGCTACTGCTTGGGC) and mn140-rev (5'T CAAAATCCT GAGTACTGATTCTG). Individual cDNA was cloned into the $\mathrm{pENTR/D}$ vector and confirmed by sequence analysis.

TGAL1 cDNA was amplified with primers TGAL1-for (5'CACCATGGAGGGTGGTAGGC TAGGAGGAGCG) and TGAL1-rev (5'TTATTCCCTTGGACGGGCGAG CCA), TGAL2 cDNA with primers TGAL2-for ( $5^{\prime} \mathrm{CA}$ CCATGGCTGATACAAGTCCAAGGACTGAT) and TG AL2-rev (5'TTATTCCCTTGGACGGGCGAGCCA), TGA L4 with TGAL4-for (5'CACCATGGGAGAAGCTAG CAG TAGTTCAGGA) and TGAL4-rev (5'TCAGAAGGCTG AATATTGGCTCTC), TGAL5 with primers TGAL5-for (5'CACCATGATCCAAAGTGACGCGTACACAGAG) and TGAL5-rev (5'TCAGAAACCGGAGAATTGATT TTG), TGAL6 with primers TGAL6-for (5'CACCA TGGGG GCGTACGACCGGCCTCCGCCA) and TGA L6-rev (5'TTAGCTTATCCCTGAATCGCGCGG), TGAL7 with primers TGAL7-for (5'CACCATGGGGGGCTCCAG AGAGGAAGATCGT) and TGAL7-rev (5'CTACATTGCC GGCCCCTCCTCCGG), TGAL8 with primers TGAL8-for (5'CACCATGGCTT ATCCTTCCACCTCTGGCATG) and TGAL8-rev (5'CTAGCCGGCGGCCGGGTGCGGCCG), TGAL9 with primers TGAL9-for (5'CACCATGGCAGAA TTGGATCACATCTTCCTC) and TGAL9-rev (5'CTAA TTTCTAGGGTTGATGGATGG), and TGAL11 with primers TGAL11-TAP1 (5'CACCGGAGAGGCTAGGA GAGGGCAGAA) and TGAL11-TAP2(5'GAAGGTTAGT CTTCAAAGTCCTTGT). Individual cDNA was cloned into the $p E N T R / D$ vector and confirmed by sequence analysis.

\section{Yeast two-hybrid constructs and assays}

Each cDNA was cloned into Gateway-compatible Y2H vectors pLexA and $\mathrm{pB} 42 \mathrm{AD}$ by $\mathrm{LR}$ recombination (Invitrogen). The Gateway-compatible $\mathrm{Y} 2 \mathrm{H}$ vectors $\mathrm{pLexA}$ and pB42AD and the $\mathrm{Y} 2 \mathrm{H}$ system have been reported previously $[21,45]$. Yeast two hybrid constructs were transformed into yeast strain EGY48 and beta-galactosidase activity was assayed by including X-gal in the medium. Beta-galactosidase activity was semi-quantitatively recorded based on the darkness of the blue color. Empty vectors ( $\mathrm{pLexA}$ and $\mathrm{pB} 42 \mathrm{AD}$ ) were included as negative controls. For each test, at least three independent yeast colonies were included and results were consistent among the three replicates. Tests were repeated and more colonies were included whenever an outlier occurred. 


\section{Generation of constructs to express non-fusion proteins in protoplasts}

cDNA of NH1, NH2, NH3, NH4, and NH5 in pENTR/D vector was cloned into a Gateway-compatible Ubi-pUC vector via $L R$ recombination. Expression of these genes was driven by the maize Ubi-1 promoter.

\section{Plasmid preparation and protoplast transfection}

All plasmid constructs were prepared with a Nucleobond plasmid midi-prep kit from Macherey-Nagel (Bethlehem, PA). For protoplast preparation, 10-14 day old etiolated rice seedlings grown in a sterile ice cream cone were used. Rice protoplast preparation and transfection was done as described before $[37,54]$.

\section{Yellow fluorescence protein (YFP) constructs and detection for split YFP assay}

Select cDNA was cloned into Gateway-compatible split YFP vectors pY736 (YFPN) and pY735 (YFPC) by LR recombination. The Gateway-compatible split YFP vectors pY736 and pY735 and the split YFP assay have been reported previously [45]. An equal amount of plasmid $(5 \mu \mathrm{g})$ was used for each protoplast transfection. Empty vectors (pY736 and pY735) were included as negative controls. Rice protoplasts were incubated for $24-36 \mathrm{hr}$ after transfection in incubation buffer. YFP detection used an Axiovert 25 fluorescence microscope (Zeiss) with an excitation wavelength of $500 / 25 \mathrm{~nm}$ and an emission wavelength of 535/30 nm (filter set 46HE). Each split YFP experiment was repeated at least once. The YFP signal strengths were compared between samples and assigned semi-quantitatively according to the results from repeated experiments.

\section{Bridged split YFP}

For each bridged split YFP experiment, a $\mathrm{Ubi-1}$ promoterdriven, non-YFP fused NH1, NH2, NH3, NH4, or NH5 construct was included, in addition to the YFPN-fused TGA and YFPC-fused RH constructs.

\section{Detection of protein expressed in rice protoplasts}

Rice protoplasts were transfected with YFPN and/or YFPC fusion constructs $(8 \mu \mathrm{g} /$ construct/transfection), together with a Ubi-Gus plasmid ( $2 \mu \mathrm{g} /$ transfection) as an internal reference for transfection efficiency. A small aliquot $(2 \mu \mathrm{l}$ out of $240 \mu \mathrm{l}$ ) of the protoplasts was used for GUS activity assay. The remaining transfected rice protoplasts were spun down 24 hours post transfection and re-suspended in $20 \mu \mathrm{l}$ of $1 \mathrm{x}$ SDS protein sample buffer (10\% glycerol, $60 \mathrm{mM}$ Tirs- $\mathrm{HCl}, \mathrm{pH} 6.8,2 \%$ SDS, $0.01 \%$ bromophenol blue, and $1.25 \% \beta$-mercaptoethanol). The amount of protein loaded in an SDS polyacrylamide gel for each sample was adjusted according to the corresponding GUS activity. YFPN fusion proteins were probed with an $\alpha$-c-Myc monoclonal antibody (9E11, Santa Cruz Biotechnology) and YFPC fusion proteins probed with an $\alpha$-HA tag monoclonal antibody (F-7, Santa Cruz Biotechnology).

\section{Co-expression analysis}

Analysis of microarray data for co-expression between two genes was performed according to the method reported before [45].

\section{Additional files}

Additional file 1: Figure S1. Yeast two-hybrid pictures for interactions between NH and TGA protein families. Yeast cells containing plasmid constructs expressing proteins as labeled were grown on medium with $\mathrm{X}$-gal for two days. Blue colors indicate an interaction between the two test proteins. The darkness of blue colors is used as the indicator for protein interaction strength. (A) NH proteins were fused to B42AD and TGA proteins fused to LexA. (B) NH proteins were fused to LexA and TGA proteins fused to B42AD.

Additional file 2: Figure S2. Split YFP pictures for interactions between $\mathrm{NH}$ and TGA protein families. Rice protoplast cells were transfected with plasmids expressing proteins as labeled. Fluorescence signals were observed under a fluorescence microscope 20-24 hours after transfection and pictures taken with $2 \mathrm{sec}$ of exposure time. (A) $\mathrm{NH}$ proteins were fused to YC and TGA proteins fused to YN. (B) NH proteins were fused to YCNand TGA proteins fused to $Y C$.

Additional file 3: Figure S3. Yeast two-hybrid pictures for interactions between $\mathrm{NH}$ and $\mathrm{RH}$ protein families. Yeast cells containing plasmid constructs expressing proteins as labeled were grown on medium with X-gal for two days. Blue colors indicate an interaction between the two test proteins. The darkness of blue colors is used as the indicator for protein interaction strength. (A) $\mathrm{NH}$ proteins were fused to LexA and $\mathrm{RH}$ proteins fused to B42AD. (B) $\mathrm{NH}$ proteins are fused to B42AD and $\mathrm{RH}$ proteins fused to LexA

Additional file 4: Figure S4. Split YFP pictures for interactions between $\mathrm{NH}$ and $\mathrm{RH}$ protein families. Rice protoplast cells were transfected with plasmids expressing proteins as labeled. Fluorescence signals were observed under a fluorescence microscope 20-24 hours after transfection and pictures taken with $2 \mathrm{sec}$ of exposure time. (A) $\mathrm{NH}$ proteins were fused to $\mathrm{YN}$ and $\mathrm{RH}$ proteins fused to $\mathrm{YC}$. (B) NH proteins were fused to YC and RH proteins fused to YN.

Additional file 5: Figure S5. Bridged split YFP pictures for detection of tertiary protein complexes between $\mathrm{NH}, \mathrm{RH}$, and TGA families. TGA proteins were fused to $\mathrm{YN}$ and $\mathrm{RH}$ proteins fused to $\mathrm{YC}$. NH proteins were expressed from the Ubi-1 promoter as a non-fusion protein. Rice protoplast cells were transfected with plasmids expressing proteins as labeled. Fluorescence signals were observed under a fluorescence microscope 20-24 hours after transfection and pictures taken with 2 sec of exposure time. (A) Interaction with YC: NRR. (B) Interaction with $Y C: R H 1$. (C) Interaction with YC:RH2. (D) Interaction with YC:RH3.

Additional file 6: Table S1. Information of Affymetrix microarray experiments.

\section{Competing interests}

The authors declare that they have no competing interests.

\section{Authors' contributions}

MC, WB, and PCR designed and revised the study. MC, DR and WB performed the experiments and collected the data. TO conducted the co-expression analyses; TO and MC analyzed the co-expression data. XC assisted with the experiments and provided technical advice. MC and WB drafted the manuscript. MC and PCR determined the final editing. All authors read and approved the final manuscript. 


\section{Acknowledgements}

This work was supported by a United States Department of Agriculture NRI grant (\#2004-63560416640) to P.C.R. W.B. was partly supported by a fellowship from the State Scholarship Fund of China.

\section{Author details}

${ }^{1}$ Department of Plant Pathology and the Genome Center, University of California, Davis, CA 95616, USA. ${ }^{2}$ College of Life Sciences, Inner Mongolia Agricultural University, Huhhot 010018, China. ${ }^{3}$ Rice Institute, Sichuan Agricultural University at Chengdu, 211 Huimin Road, Liucheng, Wenjiang, Chengdu, Sichuan 611130, China.

Received: 11 December 2013 Accepted: 3 June 2014

Published: 11 June 2014

\section{References}

1. Durrant WE, Dong X: Systemic acquired resistance. Annu Rev Phytopathol 2004, 42:185-209.

2. Ward ER, Uknes SJ, Williams SC, Dincher SS, Wiederhold DL, Alexader DC, Ahl-Goy P, Metraux JP, Ryals JA: Coordinate gene activity in response to agents that induce systemic acquired resistance. Plant Cell 1991, 3:1085-1094.

3. Friedrich L, Lawton K, Ruess W, Masner P, Speckner N, Gt Rella M, Meier B, Dinher S, Staub T, Uknes S, Metraux J-P, Kessman H, Ryals J: A benzothiadiazole derivative induces systemic acquired resistance in tobacco. Plant J 1996, 9:61-70.

4. Yoshioka K, Nakashita H, Klessig DF, Yamaguchi I: Probenazole induces systemic acquired resistance in Arabidopsis with a novel type of action. Plant J 2001, 25:149-157.

5. Gorlach J, Volrath S, Knauf-Beiter G, Hengy G, Beckhove U, Kogel K-H, Oostendorp M, Staub T, Ward E, Kessmann H, Ryals J: Benzothiadiazole, a novel class of inducers of systemic acquired resistance, activates gene expression and disease resistance in wheat. Plant Cell 1996, 8:629-643.

6. Smith JA, Metraux J-P: Pseudomonas syringae pathovar syringae induces systemic resistance to pyricularia oryzae in rice. Physiol and Mol Plant Pathol 1991, 39:451-461.

7. Schweizer P, Schlagenhauf E, Schaffrath U, Dudler R: Different patterns of host genes are induced in rice by Pseudomonas syringae, a biological inducer of resistance, and the chemical inducer benzothiadiazole (BTH). Eur J Plant Pathol 1999, 105:659-665.

8. Rohilla R, Singh US, Singh RL: Mode of action of acibenzolar-S-methyl against sheath blight of rice, caused by Rhizoctonia solani kuhn. Pest Manag Sci 2002, 58:63-69.

9. Shimono M, Sugano S, Nakayama A, Jiang CJ, Ono K, Toki S, Takatsuji H: Rice WRKY45 plays a crucial role in benzothiadiazole-inducible blast resistance. Plant Cell 2007, 19:2064-2076.

10. Morris SW, Vernoolij B, Titatarn S, Starrett M, Thomas S, Wiltse CC, Frederiksen RA, Bhandhufalck A, Hulbert S, Uknes S: Induced resistance responses in maize. Mol Plant-Microbe Interact 1998, 11:643-658.

11. Cao H, Bowling SA, Gordon AS, Dong X: Characterization of an Arabidopsis mutant that is nonresponsive to inducers of systemic acquired resistance. Plant Cell 1994, 6:1583-1592.

12. Delaney TP, Friedrich L, Ryals JA: Arabidopsis signal transduction mutant defective in chemically and biologically induced disease resistance. Proc Natl Acad Sci 1995, 92:6602-6606.

13. Glazebrook J, Rogers EE, Ausubel FM: Isolation of Arabidopsis mutants with enhanced disease susceptibility by direct screening. Genetics 1996, 143:973-982.

14. Ryals J, Weymann $K$, Lawton $K$, Friedrich $L$, Ellis D, Steiner $\mathrm{H}-\mathrm{Y}$, Johnson J, Delaney TP, Jesse T, Vos P, Uknes S: The Arabidopsis NIM1 protein shows homology to the mammalian transcription factor inhibitor IKB. Plant Cell 1997, 9:425-439.

15. Shah J, Tsui F, Klessig DF: Characterization of a salicylic acid-insensitive mutant (sai1) of Arabidopsis thaliana, identified in a selective screen utilizing the SA-inducible expression of the tms 2 gene. Mol Plant Microbe Interact 1997, 10:69-78

16. Cao H, Glazebrook J, Clarke J, Volko S, Dong X: The Arabidopsis npr1 gene that controls systemic acquired resistance encodes a novel protein containing ankyrin repeats. Cell 1997, 88:57-63.

17. Mou Z, Fan W, Dong X: Inducers of plant systemic acquired resistance regulate NPR1 function through redox changes. Cell 2003, 113:1-10.
18. Wu Y, Zhang D, Chu JY, Boyle P, Wang Y, Brindle ID, Luca VD, Despres C: The Arabidopsis NPR1 protein is a receptor for the plant defense hormone salicylic acid. Cell Rep 2012, 1:639-647.

19. Fu ZQ, Yan S, Saleh A, Wang W, Ruble J, Oka N, Mohan R, Spoel SH, Tada Y, Zheng N, Dong X: NPR3 and NPR4 are receptors for the immune signal salicylic acid in plants. Nature 2012. doi:10.1038/nature11162.

20. Cao H, Li X, Dong X: Generation of broad-spectrum disease resistance by overexpression of an essential regulatory gene in systemic acquired resistance. Proc Natl Acad Sci 1998, 95:6531-6536.

21. Chern M, Fitzgerald HA, Yadav RC, Canlas PE, Dong X, Ronald PC: Evidence for a disease-resistance pathway in rice similar to the NPR1-mediated signaling pathway in Arabidopsis. Plant J 2001, 27:101-113.

22. Chern M, Fitzgerald HA, Canlas PE, Navarre DA, Ronald PC: Over-expression of a rice NPR1 homolog leads to constitutive activation of defense response and hypersensitivity to light. Mol Plant Microbe Interact 2005, 18:511-520

23. Yuan Y, Zhong S, Li Q, Zhu Z, Lou Y, Wang L, Wang J, Wang M, Li Q, Yang D, $\mathrm{He}$ Z: Functional analysis of rice NPR1-like genes reveals that OsNPR1/NH1 is the rice orthologue conferring disease resistance with enhanced herbivore susceptibility. Plant Biotechnol I 2007, 5:313-324.

24. Bai W, Chern M, Ruan D, Canlas PE, Sze-To WH, Ronald PC: Enhanced disease resistance and hypersensitivity to $\mathrm{BTH}$ by introduction of an NH1/OsNPR1 paralog. Plant Biotechnol J 2011, 9:205-215.

25. Jun JH, Ha CM, Fletcher JC: BLADE-ON-PETIOLE1 coordinates organ determinacy and axial polarity in Arabidopsis by directly activating asymmetric leaves2. Plant Cell 2010, 22:62-76.

26. Zhang Y, Fan W, Kinkema M, Li X, Dong X: Interaction of NPR1 with basic leucine zipper protein transcription factors that bind sequences required for salicylic acid induction of the PR-1 gene. Proc Natl Acad Sci U S A 1999, 96:6523-6528

27. Despres C, DeLong C, Glaze S, Liu E, Fobert PR: The Arabidopsis NPR1/NIM1 protein enhances the DNA binding activity of a subgroup of the TGA family of bZIP transcription factors. Plant Cell 2000, 12:279-290.

28. Johnson C, Boden E, Arias J: Salicylic acid and NPR1 induce the recruitment of trans-activating TGA factors to a defense gene promoter in Arabidopsis. Plant Cell 2003, 15:1846-1858.

29. Fan W, Dong X: In vivo interaction between NPR1 and transcription factor TGA2 leads to salicylic acid-mediated gene activation in Arabidopsis. Plant Cell 2002, 14:1377-1389.

30. Zhang Y, Tessaro MJ, Lassner M, Li X: Knockout analysis of Arabidopsis transcription factors TGA2, TGA5, and TGA6 reveals their redundant and essential roles in systemic acquired resistance. Plant Cell 2003, 15:2647-2653.

31. Rochon A, Boyle P, Wignes T, Fobert PR, Després C: The coactivator function of Arabidopsis NPR1 requires the core of its BTB/POZ domain and the oxidation of C-terminal cysteines. Plant Cell 2006, 18:3670-3685.

32. Boyle P, Su EL, Rochon A, Shearer HL, Murmu J, Chu JY, Fobert PR, Despres C: The BTB/POZ domain of the Arabidopsis disease resistance protein NPR1 interacts with the repression domain of TGA2 to negate its function. Plant Cell 2009, 21:3700-3713.

33. Weigel RR, Bauscher C, Pfitzner AJ, Pfitzner UM: NIMIN-1, NIMIN-2 and NIMIN-3, members of a novel family of proteins from Arabidopsis that interact with NPR1/NIM1, a key regulator of systemic acquired resistance in plants. Plant Mol Biol 2001, 46:143-160.

34. Weigel RR, Pfitzner UM, Gatz C: Interaction of NIMIN1 with NPR1 modulates PR gene expression in Arabidopsis. Plant Cell 2005, 17:1279-1291.

35. Zwicker S, Mast S, Stos V, Pfitzner AJP, Pfitzner UM: Tobacco NIMIN2 proteins control $P R$ gene induction through transient repression early in systemic acquired resistance. Mol Plant Pathol 2007, 8:385-400.

36. Chern M, Canlas PE, Fitzgerald HA, Ronald PC: Rice NRR, a Negative regulator of disease resistance, interacts with Arabidopsis NPR1 and rice NH1. Plant J 2005, 43:623-635.

37. Chern M, Bai W, Sze-To WH, Canlas PE, Bartley LE, Ronald PC: A rice transient assay system identifies a novel domain in NRR required for interaction with $\mathrm{NH} 1 / \mathrm{O} N \mathrm{NP} 1$ and inhibition of $\mathrm{NH} 1$-mediated transcriptional activation. Plant Methods 2012, 8:6.

38. Chern M, Canlas PE, Ronald PC: Strong suppression of systemic acquired resistance in Arabidopsis by NRR is dependent on its ability to interact with NPR1 and its putative repression domain. Mol Plant 2008, 1:552-559. 
39. Fitzgerald H, Canlas PE, Chern M, Ronald PC: Alteration of TGA factor activity in rice results in enhanced tolerance to Xanthomonas oryzae pv. oryzae. Plant J 2005, 43:335-347.

40. Mukhtar MS, Carvunis A-R, Dreze M, Epple P, Steinbrenner J, Moore J, Tasan M, Galli M, Hao T, Nishimura MT, Pevzner SJ, Donovan SE, Ghamsari L, Santhanam B, Romero V, Poulin MM, Gebreab F, Gutierrez BJ, Tam S, Monachello D, Boxem M, Harbort CJ, McDonald N, Gai L, Chen H, He Y, European Union Effectoromics Consortium, Vandenhaute J, Roth FP, Hill DE, et al: Independently evolved virulence effectors converge onto hubs in a plant immune system network. Science 2011, 333:596-601.

41. Arabidopsis Interactome Mapping Consortium: Evidence for network evolution in an Arabidopsis interactome map. Science 2011, 333:601-607.

42. Ding X, Richter T, Chen M, Fujii H, Seo YS, Xie M, Zheng X, Kanrar S, Stevenson RA, Dardick C, Li Y, Jiang H, Zhang Y, Yu F, Bartley LE, Chern M, Bart R, Chen X, Zhu L, Farmerie WG, Gribskov M, Zhu JK, Fromm ME, Ronald PC, Song WY: A rice kinase-protein interaction map. Plant Physiol 2009, 149:1478-1492.

43. Bracha-Drori K, Shichrur K, Katz A, Oliva M, Angelovici R, Yalovsky S, Ohad N: Detection of protein-protein interactions in plants using bimolecular fluorescence complementation. Plant J 2004, 40:419-427.

44. Walter M, Chaban C, Schutze K, Batistic O, Weckermann K, Nake C, Blazevic D, Grefen C, Schumacher K, Oecking C, Harter K, Kudla J: Visualization of protein interactions in living plant cells using bimolecular fluorescence complementation. Plant J 2004, 40:428-438.

45. Seo YS, Chern M, Barley LE, Han M, Jung KH, Lee I, Walia H, Richter T, Xu X, Cao P, Bai W, Ramanan R, Amonpant F, Arul L, Canlas PE, Ruan R, Park CJ, Chen X, Hwang S, Jeon JS, Ronald PC: Towards establishment of a rice stress response interactome. PLoS Genet 2011, 7:e1002020

46. Kodama Y, Hu CD: Bimolecular fluorescence complementation (BiFC): a 5-year update and future perspectives. BioTechniques 2012, 53:285-298,

47. Li S, Pandey S, Gookin TE, Zhao Z, Wilson L, Assmann SM: Gene-sharing networks reveal organizing principles of transcriptomes in Arabidopsis and other multicellular organisms. Plant Cell 2012, 24:1362-1378.

48. Yeung KY, Dombek KM, Lo K, Mittler JE, Zhu J, Schadt EE, Bumgamer RE, Raftery AE: Construction of regulatory networks using expression time-series data of a genotyped population. Proc Natl Acad Sci U S A 2011 108:19436-19441.

49. Gavin AC, Bosche M, Krause R, Grandi P, Marzioch M, Bauer A, Schultz J, Rick JM, Michon AM, Cruciat CM, Remor M, Höfert C, Schelder M, Brajenovic M, Ruffner H, Merino A, Klein K, Hudak M, Dickson D, Rudi T, Gnau V, Bauch A, Bastuck S, Huhse B, Leutwein C, Heurtier MA, Copley RR, Edelmann A, Querfurth E, Rybin V, et al: Functional organization of the yeast proteome by systematic analysis of protein complexes. Nature 2002, 415:141-147.

50. Ha CM, Kim GT, Kim BC, Jun JH, Soh MS, Ueno Y, Machida Y, Tsukaya H, Nam HG: The BLADE-ON-PETIOLE 1 gene controls leaf pattern formation through the modulation of meristematic activity in Arabidopsis. Development 2003, 130:161-172.

51. Hepworth SR, Zhang Y, McKim S, Li X, Haughn GW: BLADE-ON-PETIOLEdependent signaling controls leaf and floral patterning in Arabidopsis. Plant Cell 2005, 17:1434-1448.

52. Canet JV, Dobon A, Fajmonova J, Tornero P: The BLADE-ON-PETIOLE genes of Arabidopsis are essential for resistance induced by methyl jasmonate. BMC Plant Biol 2012, 12:199.

53. Robert-Seilaniantz A, Grant M, Jones JD: Hormone crosstalk in plant disease and defense: more than just jasmonate-salicylate antagonism. Annu Rev Phytopathol 2011, 49:317-343.

54. Bart R, Chern M, Park CJ, Bartley L, Ronald PC: A novel system for gene silencing using siRNAs in rice leaf and stem-derived protoplasts. Plant Methods 2006, 2:13. doi:10.1186/1746-4811-2-13.

doi:10.1186/1471-2164-15-461

Cite this article as: Chern et al: Interaction specificity and coexpression of rice NPR1 homologs 1 and 3 (NH1 and NH3), TGA transcription factors and Negative Regulator of Resistance (NRR) proteins. BMC Genomics 2014 15:461.

\section{Submit your next manuscript to BioMed Central and take full advantage of:}

- Convenient online submission

- Thorough peer review

- No space constraints or color figure charges

- Immediate publication on acceptance

- Inclusion in PubMed, CAS, Scopus and Google Scholar

- Research which is freely available for redistribution

Submit your manuscript at www.biomedcentral.com/submit
() Biomed Central 